Article

\title{
Product-Service Systems and Sustainability: Analysing the Environmental Impacts of Rental Clothing
}

\author{
Emma Johnson * (D) and Andrius Plepys \\ International Institute for Industrial Environmental Economics, Lund University, 22100 Lund, Sweden; \\ andrius.plepys@iiiee.lu.se \\ * Correspondence: emma.johnson@iiiee.lu.se
}

check for

updates

Citation: Johnson, E.; Plepys, A.

Product-Service Systems and Sustainability: Analysing the Environmental Impacts of Rental Clothing. Sustainability 2021, 13, 2118 https://doi.org/10.3390/su13042118

Academic Editor: Sofia Ritzén

Received: 30 December 2020

Accepted: 10 February 2021

Published: 16 February 2021

Publisher's Note: MDPI stays neutral with regard to jurisdictional claims in published maps and institutional affiliations.

Copyright: (C) 2021 by the authors Licensee MDPI, Basel, Switzerland. This article is an open access article distributed under the terms and conditions of the Creative Commons Attribution (CC BY) license (https:// creativecommons.org/licenses/by/ $4.0 /)$.

\begin{abstract}
Business models like product-service systems (PSSs) often recognise different sustainability goals and are seen as solutions for the impacts of consumption and fast fashion, but there is a lack of evidence supporting the environmental claims of such business models for clothing. The research aimed to understand if rental clothing business models such as PSSs have the environmental benefits often purported by quantifying the environmental impacts of rental formal dresses in a life-cycle assessment (LCA) in a case study in Stockholm, Sweden. The effects of varying consumer behaviour on the potential impact of a PSS vs. linear business model are explored through three functional units and 14 consumption scenarios. How users decide to engage with clothing PSSs dictates the environmental savings potential that a PSS can have, as shown in how many times consumers wear garments, how they use rental to substitute their purchasing or use needs, as well as how consumers travel to rental store locations.
\end{abstract}

Keywords: product-service system; life cycle assessment; rental clothing; environmental impact; sustainable business model; consumer behaviour

\section{Introduction}

There is an emerging awareness and increasing global effort to reduce current consumption patterns to address resource depletion, climate change, and other environmental impacts. The textile and clothing industry, in particular fast fashion, contributes to resource depletion, produces large amounts of wastewater and solid waste, contributes to chemical and pesticide residues, and is known for the exploitation of workers among many other negative impacts [1]. Clothing production globally has nearly doubled in the last 15 years, although clothing use intensity has declined by nearly $40 \%$ [2]. Clothes are being consumed at higher rates than the technical lifespans of garments [3] due to increasing disposable income and the influence of fast fashion in encouraging waste. In Sweden, clothing consumption has increased by $30 \%$ since 2000 (roughly $3 \mathrm{~kg}$ per person) with the average consumption of textiles per person at $14 \mathrm{~kg}$ in 2019 [4]. Yet Swedes dispose of $7.5 \mathrm{~kg}$ per person of textile waste in the residual waste annually, of which over half of that is in a condition for reuse [5]. In addition to this waste, Swedes send another $4 \mathrm{~kg}$ of textiles per person annually to charities or second-hand [6].

A change to conventional business models (BMs) and consumption habits is needed to reduce current unsustainable impacts [7]. BMs based on ideologies under the circular economy and the sharing economy are anticipated to contribute to sustainability objectives [8] and can be seen as solutions in the fashion industry [9]. Tukker et al. (2015) has analysed and noted BMs like product-service systems (PSSs) often recognise different sustainability goals and are seen as pathways to the acceptance of service-based societies and more sustainable solutions [10]. Examples of sustainable strategies include circular solutions such as reuse, remanufacturing, or recycling, as well as ideas of moving towards access over ownership [11]. Providing a product as a service can change consumption patterns and may provide incentives for the optimisation of supply chains and product design 
to maximise the value offering to the consumer and the company. This could result in extended lifespans of products, higher use intensities, and other value chain optimisations leading to implications such as resource efficiency and dematerialisation.

In the apparel market, $71 \%$ of consumers are interested in investing in higher quality clothing and circular business models such as resale, rental, and refurbishment following COVID-19 [12]. The market for rental services for "one-off occasions and needs" such as for clothing for special occasions, luxury, and sports has increasing potential, particularly with the addition of online rental [2]. Successful business models for special-occasion wear have already been present for several years, such as Rent the Runway in the US that rented more than 800 million USD in retail value of clothing in 2014 when they exclusively offered special occasion wear [2]. Prior to the pandemic, the growth for rental business models was projected to increase by 801 million USD between 2019-2023 [13], and a 2019 survey of 20 of the top retailers indicated that $61 \%$ of them wanted to test rental models [14]. While it is uncertain of the fashion industry's future after the pandemic, there is increasing interest by consumers to reduce their consumption and engage in more environmentally-conscious practices [13].

Despite having a sustainability potential, some BMs may not translate to less consumption [15], and the sustainability outcomes of PSSs are not certain nor clear [16-19]. There is a gap between logical claims and empirical evidence of the practical application of sharing and circular economy strategies [20]. Strategies to extend product longevity for clothing is partly compromised by external factors such as changes in style and fashion obsolescence, which shortens product lifetimes regardless of the material durability [21-23]. Furthermore, the environmental benefits of reuse or servicing strategies depend on their ability to displace primary production and minimise the associated impacts [24]. Although PSSs such as clothing libraries can reduce the speed of fashion if garments are used more times, they also have the potential to promote consumption if users update their closets more frequently [25]. Some "sharing business models even facilitate consumption, e.g., by offering a service contract which includes regular replacement of a product" [26] (p. 307). The BM can influence user behaviour, for example, the payment system can affect how many items or how often consumers make a transaction. Each transaction can have an environmental impact, in particular for transportation [25]. Companies attempting to offer more sustainable products or services must be accompanied by business model innovation, else they will render as merely positive initiatives that suggest sustainability but lack the rigor to replace the dominant linear fashion business models [27].

However, it is not only the business model nor the product or design that determines the overall sustainability, but consumers' intentions, behaviours, and habits [22]. Participating in sharing initiatives such as PSSs may not prevent waste since customers who choose to rent clothes may not abstain from purchasing clothes [28]. Consumers may choose to rent clothes to increase their wardrobe choices, rather than replace their normal purchasing. Corvellec and Stål (2017) suggest that rental clothing BMs offer consumers a way to avoid the waste responsibility that would usually come with clothing ownership [28]. The benefit of a PSS offering depends on the extent that production and ownership are substituted by rental, and this extent can be understood as a replacement rate (RR) [29]. A 1:1 RR of reused goods for purchased goods is unrealistic [29], and a few studies have found that the overall environmental benefit of textile reuse is highly influenced by the percentage of substitution [30-32]. For instance, Farrant et al. [33] found that in Sweden, the purchase of 100 second-hand garments replaces about 60 new garments. That study found that the collection, processing, and transportation required for the reuse of second-hand clothing had insignificant impacts compared to the environmental savings from avoided primary production; however, this might not be the same for rental since the associated BMs involve multiple users and a need for increased transportation [22].

Since clothing rental can offer customers classic or unique high-quality fashion items without a commitment to ownership [23], it is attractive because of reduced fashion costs and positive impacts on disposable income, potentially resulting in rebound effects. Re- 
bound effects can be understood as the environmental consequences of when the environmental impacts of a supposed improvement become less than anticipated due to changes in behaviour such as a direct increase in consumption levels or other substitutional effects among other product/service categories [34]. The potential for absolute resource decoupling in PSSs only occurs when accounting for the potential rebound effects from changes in user behaviour [35]. It is difficult to identify and measure how shared clothing can impact the environment since there is no clear information on whether consumers substitute conventional behaviour with sharing, or if it is seen as a complement and further encourages consumption.

\subsection{Aim and Scope}

This research aims to progress the understanding of the potential environmental sustainability outcomes from PSSs. A business-to-consumer (B2C) use-oriented PSS for clothing is used as a case study to address the following research question: How do user behaviour and business model configuration impact the environmental effects of PSS business models in the clothing rental segment? The research is based on a comparative life-cycle assessment (LCA) of a rental business model (PSS) vs. a linear (ownership) model of dress consumption. LCA is one method that can be used to analyse and quantify the environmental impacts for PSSs along the life-cycle from a system perspective [22,35]. The research examines clothing consumption behaviour in relation to business models and quantitatively evaluates the associated environmental impacts. Furthermore, it explores how variations in these behaviours affect the impacts and suggests how changes to consumer behaviour in rental business models can improve the environmental potential of PSSs.

The scope focuses on use-oriented PSS for clothing, meaning rental clothing business models. Shared or rental clothing in this research entails facilitation of use and provision of access. Second-hand clothes are excluded since that indicates ownership rather than access. The case company is specifically on rented pre-owned, formal dresses. The research is analysed with geographical restrictions to Sweden, as transportation infrastructure and energy mixes are specific to Sweden in which these factors may be highly influential in the results. Furthermore, consumer behaviour data collected is specific to customers already engaged in rental with the case company.

While it would be interesting to include all three pillars of sustainability (environmental, social, and economic factors), environmental impacts are the sole focus in this study. The environmental implications of rental are complex to map, and both methods and indicators for environmental assessments are different from those used to assess the economic and social impact dimensions. Methods like life cycle costing (LCC) and social life cycle assessment (SLCA) can be used to analyse the other dimensions of sustainability of PSSs [36], but LCA is the most discussed method in literature [37].

\subsection{Background: PSSs as Sustainable Business Models}

This section summarises the characteristics of PSSs and positions them in relation to the sharing economy and circular economy in order to understand the elements of BMs with the potential to fulfil sustainability objectives.

Research regarding BMs lacks a consensus on a consistent definition, although most definitions share the idea of value creation as a central tenet in the description, as indicated most notably by Zott, Amit, \& Massa (2011); Lüdeke-Freund, Gold, \& Bocken (2019); Osterwalder \& Pigneur (2010), and Teece (2010) [27,38-41]. A BM can be broadly understood as a business's organisational architecture [40] that explains how it creates, delivers, and captures values [39] through its activity systems [41]. Values and strategies of the circular economy and sharing economy show up in various BM archetypes categorised as sustainable in academia, and archetypes of BMs that facilitate reuse through the provision of services are often based on the literature on PSSs as shown by Bocken, Short, Rana \& Evans (2014) [42]. The concept of PSSs offers BM templates with service-oriented value proposi- 
tions that enable sustainable outcomes [43]. Armstrong, Niinnimäki, Lang \& Kujala (2016) describe a PSS as a "social archetype of business models for sustainability" [44] (p. 21), and Mont (2002) states that the benefits of a PSS are characterised by the potential to change consumer behaviour and reduce the need for ownership by introducing alternative access for product use [45]. Bocken et al. (2014) note that PSSs can incentivise manufacturers to reduce product volume by making longer-lasting products that can be easily repaired [42].

Tukker (2004) classified PSSs into three categories: product-oriented, use-oriented, and result-oriented [41]. This study focuses solely on use-oriented PSSs, where a product is still central to the business model offering, but the product stays in ownership with the provider and is made available to several users at different times [46]. Products are not sold in a use-oriented PSS and can be offered in three forms: product leasing, product renting or sharing, and product pooling [46] (p. 248-249). An example of how these forms of use-oriented PSSs could show up in the apparel industry are shown in Figure 1, which have certain implications on how consumers behave and engage with products.

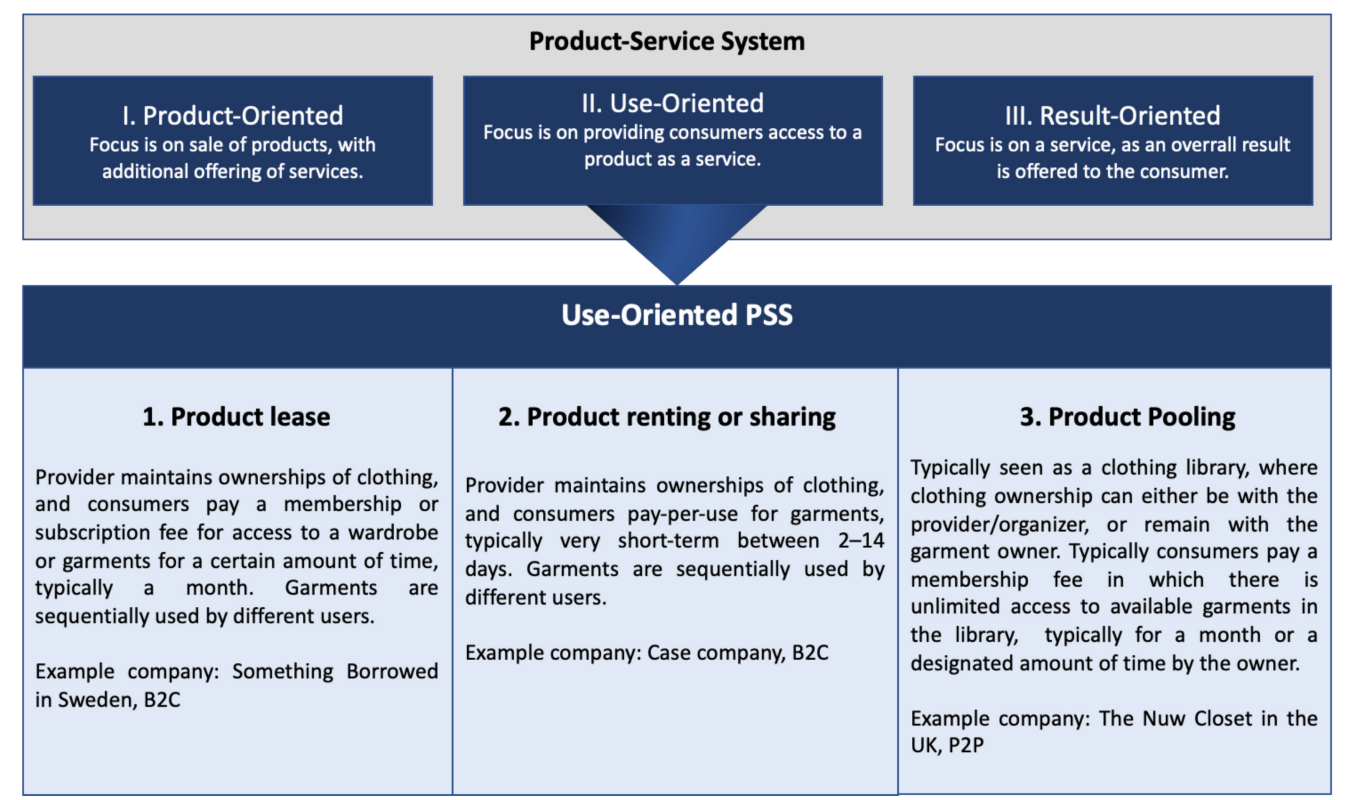

Figure 1. Types of PSS and practical examples of use-oriented PSSs in the apparel industry [47].

PSSs have been linked with the sharing economy $[26,48]$, as well as been cited as a pathway to fulfil circular economy strategies [34]. However, not all types of PSSs utilise the strategies and goals corresponding to these concepts [35]. Nevertheless, PSSs can encourage circularity, for example, by selling usage rather than ownership, "and breaking the link between profit and production volumes" [42,49] (p. 480). PSSs can facilitate circular strategies through product sharing and extension of service life [34,49], as well as promote dematerialization through access-based consumption, increased use intensities of products, and better company control over products' lifetimes $[44,46]$. These strategies are associated with a "slow the loop" strategy from circular principles with the aim to extend the service life of the product by reuse, repair, and sometimes remanufacture [38]. This keeps products at their highest value as long as possible, which is where clothing rental BMs fit in [38] since the company's goal is to continue rental of the same garment without changes to the product itself. The objective to slow the loop is also where the sharing economy fits as a concept due to the idea of sharing resources to maximise use [50] to decrease consumption and prevent the need for more products [51]. Although the circular and sharing economy can be understood differently, they overlap in their strategy to increase reuse. While some authors perceive the sharing economy as a means to realise the circular economy [15,51-53], Ref. [54] notes that understanding these concepts in conjunction may help to increase transition to business models with lowered environmental impacts. 


\section{Materials and Methodology}

\subsection{Research Design}

Case study research is used as a method [55-57] to test the cause-and-effect relationships between BMs and their environmental impact. Data is derived from the literature and a consumer survey and interviews with a case company in Stockholm. The case company is a $\mathrm{B} 2 \mathrm{C}$ formal rental dress company that can be categorised as a use-oriented PSS. The company offers access to second-hand formal dresses as its product inventory, with the additional services of laundry, clothing maintenance, and repair. Qualitative and quantitative data on various aspects of the company's business model and activities were collected through questionnaires to the company's CEO. Data on consumer behaviour was collected through a user survey and complemented with secondary data gathered from the literature, as well as databases available in the LCA software. While there are criticisms of generalisability to the use of case studies, [58] argues that concrete knowledge is context-dependent, and details from real-life situations can be of more value than universal predictive theories. This case study offers a description and explanation of the causal mechanisms and contextual factors that alter the environmental impact outcomes, such as how certain characteristics of the business model (transport, rental time frame, company proximity to consumers, etc.) and certain consumer behaviour characteristics (use intensity, replacement rate, transport mode) can alter the environmental sustainability of the case company. The case study can be generalised then judging by its transferability to different contexts of similar understandings [55]. It is an embedded case study [56], with the case company as the central unit of analysis, and consumer behaviour characteristics as the smaller units.

The study uses a life-cycle assessment (LCA) as a tool to explore the potential environmental trade-offs in the case company in comparison to a hypothetical linear BM. LCAs can provide a system's perspective and capture possible burden-shifting of environmental impacts along different life-cycle stages and value chains [3,34]. However, LCA is limited in its ability to effectively capture the impacts of variations in actual behaviour [7], as well as capturing indirect systems and rebound effects [35]. The use of LCA to explore the impacts of PSS lack guidelines, for example, from the ISO standard 14,040 for LCA, and there has been little research to focus on such strategies [19]. However, the limitations of the LCAs are not critical in addressing the problem nor the research question because of its ability as a tool to provide several different indicators to summarise environmental impacts with the consideration for many different environmental issues [3]. According to [11], LCA is the best method to evaluate reuse, as it is capable of identifying the associated benefits of reuse based on the avoided impacts from production. LCAs have been increasingly used for the clothing industry by authorities, researchers, and the industry itself in environmental product declarations and product design $[3,59]$.

\subsection{Data}

A series of questionnaires were sent to the case company to collect company-specific data. Data collected was both qualitative and quantitative, with some information directly from the CEO and other information from the company's sale system. The data represents the period from May 2018 (beginning of operations) until February 2020 and included user, garment, and business activity data. This data along with the behaviour survey helped inform the activities modelled in the LCA. Data considered relevant for the model included the average number of rentals per user, company laundry activity, general dress material composition, general dress mass, number of rentals per garment, and average time frame of rentals.

A digital survey was conducted in both English and Swedish and sent only to customers who were signed up for the case company's newsletter. The purpose of the survey was to assess different behavioural consumption patterns of how users engage with the rental company. It was comprised of two main parts: the first focused on the consumer's typical purchasing and use behaviour for formal dresses, and the second focused on the 
consumer's relationships with the case company in their rental participation and its effect on their normal purchasing. A third part asked hypothetical questions on how consumers would behave if there would be a different rental BM in place. While a survey does not typically capture actual behaviour, it provides an indication of the behaviour of users engaged in the platform. There were 57 total respondents out of the 856 active users. Information from the survey was used to gather data for consumer activities in the life-cycle inventory in the LCA. The survey contributed data on garment use intensity, the number of dresses purchased yearly, transport modes and consumer transport distance, washing behaviour, and RR for rental dresses for purchased dresses.

\subsection{Life-Cycle Assessment}

Decisions on the selection of the functional units (FUs) to be explored in this study were based on the consumer survey and reviewed literature. Previous LCA studies addressing clothing PSSs were used to help understand the important characteristics of clothing PSSs and provided different perspectives on how to conduct LCAs for shared clothing. These studies indicated important factors such as rental pick-up distances and transport modes [25], changes to the material and garment mass [60], number of uses and laundry variations, and different electricity mixes for activities in the use phase [61]. The LCA was conducted through the software SimaPro, (version 9.0 by PRé Sustainability, Amersfoort, Netherlands) and follows the guidelines stipulated in the ILCD handbook (2010) described below in further detail.

\subsubsection{Goal and Scope Definition}

This study took a user-oriented perspective (as opposed to product/service perspective or organisational perspective [7]). The FUs simulated in the model account for differences in user behaviour when engaging with the analysed case of clothing PSSs. Since consumers choose to rent clothes for different reasons which result in different behaviours and potential impacts, three FUs were developed: "one average use", "user dress needs for 4 years satisfied by purchasing" and "user dress needs for 4 years satisfied by uses/wear occasions". These FUs offer different perspectives on the impacts of consumption in PSSs and in traditional ownership-based consumption. The reference flows (RFs) are described in Table 2.

The geographical boundaries in the use phase are specific to Stockholm, Sweden since consumption behaviour and usage likely differ in the capital city compared to other areas for a variety of reasons. Transportation scenarios are also specific to Stockholm. Product end-disposal (predominantly municipal incineration) is generalised to Sweden. Production data is comprised of an electricity mix of 7 countries that dominated Swedish clothing importation between 2013-2017 [62]. The time frame for use is determined by the FUs. "One average use" accounts for one wear occasion of a garment. The other two FUs account for the use of 4 years based on data from [63]. The environmental impacts of staff, capital infrastructure, and packaging are excluded from the study. Garment details such as zippers and buttons are also excluded.

\subsubsection{Lifecycle Inventory (LCI)}

The LCI includes the data collection of all the inputs and outputs for each stage of the product/service life-cycle [64]. The attributional approach (ALCA) taken in this study implied the use of average data and exclusion of marginal data. ALCAs partition through allocation by estimating "what share of the burdens of the multifunctional process belongs to", including the input materials and energy in the product under investigation [65] (p. 12). Average data includes the "environmental burdens for producing a unit of the good and/or service in the system", whereas marginal data considers "the effects of a small change in the output of goods and/or services from a system of environmental burdens of the system" [66] (p. 3). The decision to use the ALCA approach was taken since the study compares different scenarios from an individual consumer perspective, i.e., a 
"micro-level decision", which is suggested for "product comparison" and "comparative assertion" studies [67]. The ecoinvent v3 database was used with the "allocation, cutoff by classification, unit processes" database in SimaPro. This considers an average supply of products allocated by their market value, similarly to "allocation at the point of substitution model". However, the cut-off classification differs in that it does not credit primary producers with the benefits for the provision of recycled materials, and the recycled materials bear an impact only in the processing of the material $[68,69]$. "Unit process" was selected, as this is more transparent by offering a clear link and traceability of inputs from upstream processes [68]. Default allocation methods from the processes selected in the ecoinvent database are used along with allocation by material mass.

Two life-cycle flow models were developed-one for a garment in a PSS (based on the case company) and another model for a garment in retail (based on conventional consumption data from literature) as shown in Figure 2. The technological and geographical representativeness of data was considered for all processes.

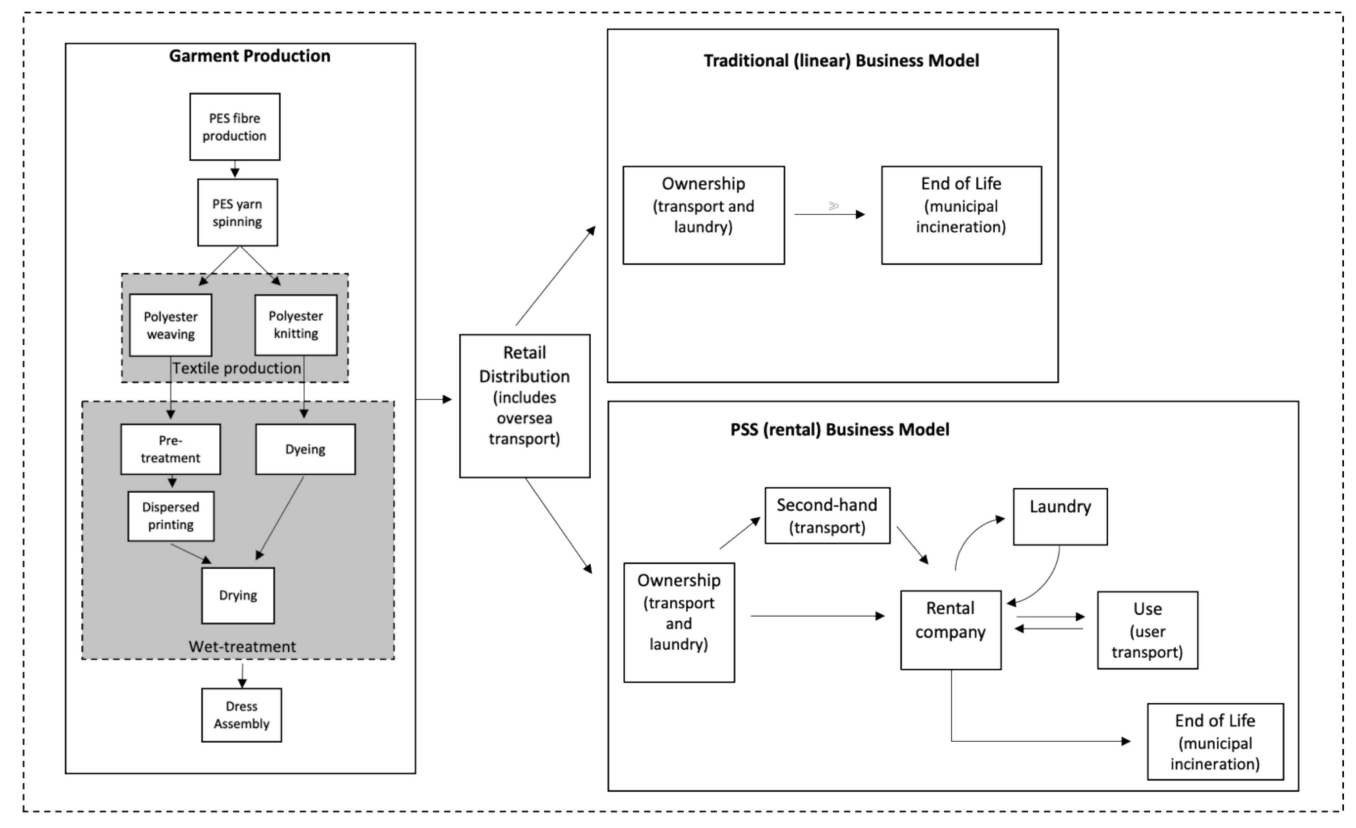

Figure 2. Life-cycle of a linear business model vs. the rental case company.

The production processes modelled for the linear and rental BMs were identical since the case company offers rental of pre-used dresses and does not produce any dresses. Dress production data was taken from the LCA of a polyester dress [62,70]. This was considered relevant as most of the dresses from the case company are made from polyester. The top three dresses rented by the company are made with a mix of materials including polyester, with two dresses consisting $100 \%$ of polyester. Buttons, zippers, and closure details or additional dress accessories were excluded as they were presumed to have an insignificant effect due to their little relative mass to the garment. The distance and process data for transoceanic shipment of garments from production countries to retail stores in Sweden were taken from [62,70]. Resources needed for the retail store such as building infrastructure, heat and electricity, and transport for retail staff were excluded.

The use phase involves the purchasing of dresses by accounting for the material needed to produce the garments, the associated transport to purchase or rent, and the laundry activities associated with the use intensity. The RR of rental for purchased dresses is based on a combination of company data and survey responses. A weighted average for the RR based on survey responses was calculated as $70 \%$. However, data from the case company was calculated to be a $33 \%$ RR. Due to this contrast, three different RRs are tested: $33 \%, 50 \%$, and $100 \%$ replacement rate. 
Transport is accounted for during the use phase in the linear BM scenarios by including consumer travel to the store and back home to purchase a garment. Transport in the PSS BM scenarios are accounted for by including: (a) travel for consumers to the rental store and back home for pick-up and drop-off; (b) company laundry transport for dresses from the store to the off-site laundry location and back; and (c) consumer travel to the store and back to purchase a garment in addition to rental for some scenarios. The most popular transport mode combination found from the survey was used as the average and used to model all transportation unless noted otherwise. An additional three transport scenarios were created based on the survey, which were used to test the impact of consumer rental transport in a sensitivity analysis. The transport modes used can be found in Appendix A, Table A1. Travel distance for consumer transport to purchase and rent clothes is based on secondary data from literature $[61,62,71]$ with consideration for data collected from the author's survey and time estimations using Google Maps. Transport distance for company laundry was taken from the company questionnaires.

The use intensity is understood and used in two different ways: the number of wear occasions for one individual in a FU, the number of wear occasions for a garment in a FU. Use intensity applied in the first way with an individual consumer perspective is used to calculate the number of wash and iron cycles for each scenario. Use intensity applied in the second way with a garment perspective indicates the total amount of times a garment is assumed to be worn. In a linear scenario, this means the total number of times a garment is used in its lifetime by the owner. Use intensity in this way is used to divide the impacts of production or other activities by the number of total wear occasions or uses. The total number of uses for a purchased garment was calculated to be 3.12 uses/wear occasions from survey responses. This is lower than what is found in the literature $[25,71]$ but is assumed suitable for formal dresses since it is perceived that there is much less of a need for such attire in comparison with all categories of dresses that have been analysed in the literature. The total amount of uses and/or users is used to support the calculation of other reference flows such as in production, transport, and end-of-life (EoL).

The same characteristics for laundry loads are assumed for both consumers and the case company since residential washing machines are used for both. The rental company's care of the garments seems to be a similar treatment to average consumer laundry, except for increased washing cycles and additional transport. Laundry cycles were calculated according to the number of times a garment is worn with the average stated washing behaviour by respondents in the survey and compared with the literature [62,71]. Since formal dresses require specific laundering care, a lower wash temperature and smaller wash load were assumed compared to an average wash load with everyday garments. A $1 \mathrm{~kg}$ load of laundry in $30^{\circ} \mathrm{C}$ is assumed in both the linear and PSS systems, based on data from [72,73]. No garment drying is modelled in the process since dresses are air-dried by the company, and this is assumed to be the same for consumers with ownership. It was assumed also that drying rooms (torkrum) were not used, as heat could damage the dresses, and [70] states that energy use in these types of rooms can vary greatly. Ironing is modelled with every wash cycle based on company data.

The waste treatment method modelled for garments in both the linear and PSS system is municipal incineration in the Swedish context. This is a simplified end-of-life scenario but is considered accurate since most streams will eventually end up in incineration [74].

\subsubsection{Life-Cycle Impact Assessment (LCIA)}

The general impact categories in the LCIA can be broadly summarised as resource use, human health, and ecological consequences [64] which are divided into subcategories. A midpoint approach was chosen for the LCIA, and the ReCiPe Hierarchist midpoint method was selected. A midpoint approach integrates the precautionary principle more than the endpoint approach, where there is no consideration for impacts that cannot be modelled or are more unknown [66]. ReCiPe Hierarchist normalisation methods are based on a study by [75], utilizing the population of EU25+3 of 450 million citizens [76], in which 
normalised results are expressed as person equivalents, or the annual impact of an average European person in the year $2000[68,76]$. To determine relevant impact categories, LCAs on garments $[29,33,60,62,70,77]$ were reviewed to understand the important impacts from an industry and research perspective that should be considered. This was taken into account in concurrence with the significant impact categories from the results. Results were normalised and the following categories were analysed: freshwater ecotoxicity, human carcinogenic potential, and global warming potential.

\subsubsection{Interpretation}

Results are presented separately for the three FUs, and the following analyses were conducted:

- Variation analysis: This was conducted by testing three different FUs, along with alternative scenarios within each. There were 14 total scenarios;

- Dominance analysis: This was conducted by analysing which life-cycle stages in the scenarios contribute the most to environmental impact categories. It also analysed how increased usage in both the linear and PSS BMs can reduce the share of the production impacts;

- Sensitivity analysis: The use intensity of garments was tested using the FU "one average use", where the linear and PSS scenarios were tested for low, average, and high use intensities. The RR for purchased dresses and the RR for wear occasions was tested in both of the " 4 years of consumer dress need" FUs, and variation in transport mode was tested in all three FUs.

\section{Results}

An overview of the case company's BM and activities are summarised in this section, followed by the results of the consumer survey which details consumer behaviour and interaction with the case company. The section then discloses the environmental impact results from the LCA.

\subsection{A Case Study: Formal Dress Rental in Stockholm}

The case company is a B2C clothing library in Stockholm, where customers can rent formal and high-end dresses. Customers pay-per-use for dresses and can choose to rent dresses for 2, 4, 7, or 14 days. Most of the dresses that the company rents are second-hand, in which $60 \%$ of the dresses are procured through the company's own purchasing through second-hand shopping or over-stock. About $40 \%$ of the dresses are from clients who rent out their dresses. The company offers an online platform as well as a physical location, and laundry and repair are taken care of by the company. Customers can pick-up dresses from the store or order online. Dresses are offered throughout Sweden, although the current customers live in the Stockholm area, and most choose to pick-up their dresses rather than order online.

The company began business in May 2018, and the data used in the study is from its opening until February 2020. The company has a total of 856 clients and rents an average of 50 dresses per month. The company expected to grow twice as much in 2020 compared to 2019, although this likely changed due to consequences from COVID-19. Clients average 1.09 rentals per user from the time period stated previously. The company offers 317 active dresses that are rented and owned by the company and 163 actively rented dresses that belong to clients. Due to the large dress assortment and the company's relatively new market presence, it was estimated that the average number of times a garment is currently rented is two times. However, some dresses have been rented many more times, with the top three dress rentals having been rented 17 times, 15 times, and 12 times. The company estimates that based on the top-rented garments' quality and wear, they could be worn between 5-15 more times. 


\section{Rental Clothing and Consumption Behaviour}

The section summarises the main findings from the consumer survey and provides insight on consumer purchasing frequency, use intensity, and laundry frequency in a linear BM. It also summarises consumer transport behaviour and patterns for the linear and PSS $\mathrm{BM}$, along with consumer rental motivation and substitution of rental for purchased dresses. Lastly, it discusses responses to hypothetical changes to the rental BM and categorises consumer consumption types.

The purchasing frequency of formal dresses by the case company's users was calculated as a weighted average of 1.5 formal dresses purchased annually. Most respondents wear their purchases of formal dresses 3 times or less (68\%), with just $4 \%$ stating that they wear one formal dress more than 10 times. A weighted average was calculated for consumers to wear formal dresses an average of 3.12 times. The majority of respondents $(63 \%)$ stated they only wash their dresses when it appears dirty, with $26 \%$ of respondents washing after every use and $11 \%$ after every other use.

Consumers were asked about their primary and secondary transport modes in how they travel to the store to purchase items and how they travel to the case company to rent. Consumers answered very similarly for both cases, with the metro (tunnelbana) as the most popular form of transport as the primary mode ( $47 \%$ of respondents traveling to shop, and $54 \%$ of respondents traveling to the rent). The bus is the most popular secondary form of transport (48\% of respondents traveling to shop and $32 \%$ of respondents traveling to rent). Four transport scenarios were created as the most common forms of primary and secondary transport: metro and bus (average), metro and walking, biking and metro, car and metro. Consumers were also asked how they planned their trip to the case company rental store, in which $55 \%$ of respondents stated they combine the visit to the rental store location with other errands, and $45 \%$ stated they make a point to just go to the rental store.

When customers were asked how renting dresses from the case company affects their normal shopping behaviour, respondents selected a number on a scale from $0-10$, with 0 representing no impact, to 10 as $100 \%$ substitution of rental dresses for purchased dresses. Substitution refers to the RR. A majority of the respondents indicated that they considered their participation in renting dresses as a substitution for buying dresses, with a weighted average of respondents' reported RR as $70 \%$. Fifty-three percent of respondents stated that they still purchase dresses even though they rent. When respondents were asked an open question inquiring the reasons why they felt they still needed to buy formal dresses, the following reasons were the most common: the limited number of dresses available to rent, if consumers wanted to wear a dress many times, and if dresses were well-priced to purchase. Many respondents commented that they purchase dresses because of a need to have casual or everyday dresses that would be worn more often, indicating that the rental company fulfils a very specific niche of clothing for formal and special events.

The primary motivator to rent for most respondents was to "avoid having to purchase a dress" (35\% of respondents), followed by "environmental concerns" (21\%). The most common secondary motivator to engage in rental was to "wear unique dresses" $(33 \%)$, and the lowest motivator for the majority of respondents $(72 \%)$ was having "influence from friends to rent". When asked if they would want to rent more dresses if the case company would offer a membership fee rather than pay-per-use for their dresses, $70 \%$ of respondents stated that they would not. Of respondents who did indicate their interest in unlimited rentals, $88 \%$ of them said they would rent dresses as needed, not at the same time. This would be impactful for the specific BM of the case company, as renting dresses as needed implies an increase in consumer transport.

Respondents were asked to identify a consumer shopping profile that they felt described their behaviour best (Table 1). Respondents identified the most with the "stand-out" profile (51\%). When consumer profiles were assessed individually, there was some variation in the respondent's garment usage, purchases, and stated RR of rental dresses over purchased. The use intensity and the number of purchased dresses did not vary greatly, but the RR varied quite a bit (Table 1), with the lowest stated RR as $46.70 \%$ for influencer con- 
sumer profiles and 90\% RR for eco-friendly consumer profiles. The consumer profiles did not have any patterns in terms of demographic characteristics even though age, education level, and annual income were collected. The consumer profiles suggest that rental clothing companies are most attractive to consumers desiring to have unique clothing, followed by those motivated to save money. However, rental clothing appears to be more successful in replacing ownership for consumer types that identify with eco-friendly shopping as well as the desire to fit-in in terms of their style.

Table 1. Consumer shopping profiles and behaviour variation.

\begin{tabular}{cccc}
\hline $\begin{array}{c}\text { Consumer } \\
\text { Types }\end{array}$ & Characteristics & $\begin{array}{c}\text { \% of } \\
\text { Respondents }\end{array}$ & $\begin{array}{c}\text { RR of Rental Dresses } \\
\text { for Purchased }\end{array}$ \\
\hline Influencer & Buys latest styles & $5 \%$ & $46.70 \%$ \\
Eco-friendly & Buys sustainable alternatives & $7 \%$ & $90 \%$ \\
Fitting-in & Buys similar styles to friends & $5 \%$ & $80 \%$ \\
Bargain & Buys cheaper alternatives & $20 \%$ & $59.10 \%$ \\
Avoid & Buys only when needed & $12 \%$ & $62.90 \%$ \\
Stand-out & Buys unique clothing & $51 \%$ & $73.10 \%$ \\
\hline
\end{tabular}

\subsection{Environmental Impact by Functional Unit}

Three functional units are presented since different motivations to rent implies that consumption satisfied different needs. The FU "one average use" is presented first, and is considered a narrow definition of the FU that provides a somewhat simplistic but more concrete understanding of the impact associated with one use of a dress in a linear vs. a rental scenario. This involves dividing certain activities in the LCI such as dress production, by the total number of uses or users in the scenario. Although it factors in variations in the use intensity of a garment, the scope of the FU is limited since it does not consider how rental clothing can displace production for purchased clothing.

The other two FUs are more broadly defined, in which " 4 years of consumer needs" for a formal dress are analysed. As some respondents from the survey stated their primary motivation to rent was to "wear unique dresses" or "to access different styles", then the FU "user dress needs for 4 years satisfied by purchasing" was analysed. Other respondents who appear to have more satisfaction with the number of times a garment can be worn, such as consumers who stated their primary motivation to rent was to "avoid having to buy a dress", or "to save money", or "for environmental concerns" is addressed by the FU "user dress needs for 4 years satisfied by the number of uses or wear occasions". These FUs include a RR where rental dresses replace linear dresses to some degree either by the garment itself or by the wear occasion. These more broadly defined FUs take a systems-thinking approach by considering rental systems' potential to displace linear consumption systems on a specific product-basis. Although these FUs include more effects from consumer behaviour, more assumptions have to be made which introduces more uncertainty. A description of the scenarios analysed for each FU can be found in Table 2.

The most significant impact categories out of the 18 midpoint indicator categories for all three FUs were freshwater ecotoxicity (FETP) and human carcinogenic toxicity (HTPc). The results for FETP and HTPc, as well as global warming potential (GWP) are analysed amongst the scenarios. 
Table 2. Scenarios and associated FUs including the life-cycle stages from Figure 2.

\begin{tabular}{|c|c|}
\hline Linear Scenarios & PSS Scenarios \\
\hline \multicolumn{2}{|c|}{ FU: One Average Use of a Formal Dress } \\
\hline $\begin{array}{l}\text { L 1.1: One average use of a purchased dress } \\
\text { with average }(3.12) \text { total wear occasions. }\end{array}$ & $\begin{array}{l}\text { PSS 1.1: One average use of a rental dress with } \\
\text { an average (11) total of rentals/users. }\end{array}$ \\
\hline $\begin{array}{l}\text { L 1.2: One average use of a purchased dress } \\
\text { with low (1) total wear occasions. }\end{array}$ & $\begin{array}{l}\text { PSS 1.2: One average use of a rental dress with } \\
\text { a low (2) total of rentals/users. }\end{array}$ \\
\hline $\begin{array}{l}\text { L 1.3: One average use of a purchased dress } \\
\text { with high (11) total wear occasions. }\end{array}$ & $\begin{array}{c}\text { PSS 1.3: One average use of a rental dress with } \\
\text { a high (20) total of rentals/users. }\end{array}$ \\
\hline \multicolumn{2}{|c|}{ FU: 4 Years of Consumer Formal Dress Needs Satisfied by Purchasing } \\
\hline $\begin{array}{l}\text { L 2: Four years of dress purchasing ( } 1.5 \text { per } \\
\text { year) with average total wear occasions. }\end{array}$ & $\begin{array}{l}\text { PSS 2.1: Four years of combined dress } \\
\text { purchasing and rental with a } 33 \% \text { RR. } \\
\text { PSS 2.2: Four years of combined dress } \\
\text { purchasing and rental with a } 50 \% \text { RR. } \\
\text { PSS 2.3: Four years of combined dress } \\
\text { purchasing and rental with a } 100 \% \text { RR. }\end{array}$ \\
\hline \multicolumn{2}{|c|}{ FU: 4 Years of Consumer Formal Dress Needs Satisfied by Use } \\
\hline $\begin{array}{l}\text { L 3: Four years of dress use ( } 4 \text { uses per year) } \\
\text { with average total wear occasions. }\end{array}$ & $\begin{array}{l}\text { PSS 3.1: Four years of dress use with } \\
\text { combined dress purchasing and rental with a } \\
\text { 33\% RR of wear occasions. } \\
\text { PSS 3.2: Four years of dress use with } \\
\text { combined dress purchasing and rental with a } \\
\text { 50\% RR of wear occasions. } \\
\text { PSS 3.3: Four years of dress use with } \\
\text { combined dress purchasing and rental with a } \\
\text { 100\% RR of wear occasions. }\end{array}$ \\
\hline
\end{tabular}

\subsection{Impact of One Average Use}

The scenarios for the FU "one average use" shows how differences in the total number of users for a garment change the impact of one average use in a PSS, and the total number of uses of a garment in a linear system. The total number of uses is important since the increase in overall usage decreases the share of the environmental burden from the production stages, as well the transoceanic shipment for retail distribution, and the consumer's trip to the store to purchase an item. The increased usage however, does not impact the transport for rental, since 2 trips are still needed for every rental (pick-up and drop-off of the item).

The PSS scenario with the greatest number of users (PSS 1.3) (see Figure 3a) has the lowest impact contribution to freshwater ecotoxicity potential than the other PSS scenarios. However, the linear scenario with the greatest number of uses (L 1.3) contributes the lowest impact to this category overall, $20 \%$ less than the high-user PSS scenario (PSS 1.3). Although PSS 1.3 reduces the percentage of the impact from production by increasing the total number of users/rentals (Figure 3b), the high amount of transportation required for rental results in a higher impact contribution in this category than the high-use linear scenario. The low-use linear scenario (L 1.2) has the highest impact in this category, resulting from the high impacts of production (Figure 3b). Although the lowest PSS user scenario (PSS 1.2) has a very low amount of total uses, its impact in this category is $40 \%$ lower in this category than L 1.2 despite increased transportation needs. The average use scenarios for the linear system (L 1.1) and PSS system (PSS 1.1) have relatively the same overall contribution to the category, but the impact from L 1.1 comes primarily from production $(70 \%)$ and the impact from PSS 1.1 comes primarily from consumer rental transport (50\%) (Figure 3b). This indicates that the scenarios with the lower impact potential for freshwater ecotoxicity are when purchased dresses are used many times by garment owners themselves, followed by a high number of users to rent the same garment. 


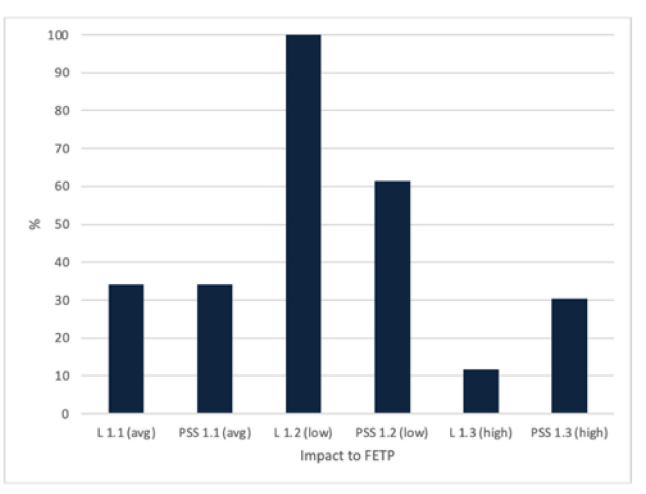

(a)

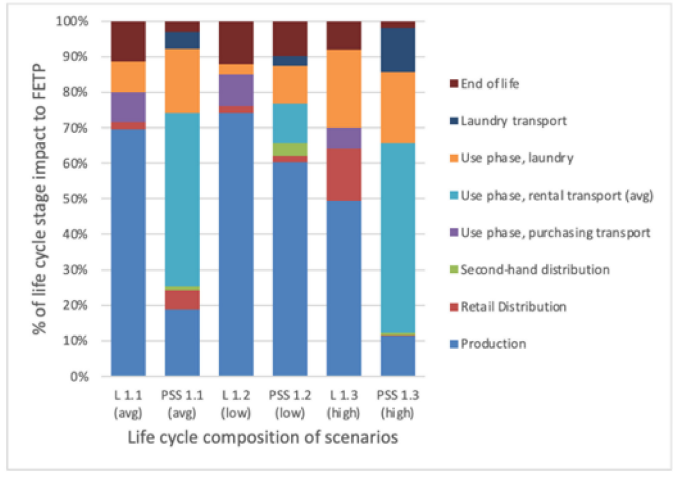

(b)

Figure 3. Characterisation results by the percentage of the impact of linear vs. rental scenarios for FETP for "one average use". The highest scores of the category are set to $100 \%$ and other values are set as a relative percent (a); Life-cycle stage contribution for FETP for each scenario for "one average use" $^{\prime \prime}$ (b).

When alternative transport modes are included, all PSS scenarios with the high-impact transport combination become the highest contributors, above the linear scenarios (see Figure A1). L 1.3 remains the scenario with the lowest impact, followed by PSS 1.3 with one of the public transport combination modes. This means that increased use by garment owners remains the least impactful for freshwater ecotoxicity, followed by high user rental when using public transportation. The benefit for PSS changes when using high-impact transportation, as PSS 1.3 with car transport has a 75\% higher impact in this category than PSS 1.3 with average transportation. All PSS scenarios excluding car transport scenarios have a lower impact than the low-use linear scenario (L 1.2), indicating that all rental scenarios have a lower impact than low usage for a dress owner if public transportation is used (see Figure A1).

The human carcinogenic toxicity potential was highest in L 1.2, followed by PSS 1.2, (see Figure $4 \mathrm{a}$ ), in which $81 \%$ and $63 \%$ of the impact are contributed from production (Figure $4 \mathrm{~b}$ ). This is followed by PSS 1.1 (with 17\% impact contribution from production and $56 \%$ impact contribution from rental transport), then PSS 1.3 with 59\% impact contribution from rental transportation. This indicates that rental transport is responsible for a large share of impact contribution to this category, meaning that increased use of a garment such as in PSS 1.3, can increase the impact for human carcinogenic toxicity if increased use is associated with more transport. This is shown as L 1.1, where a purchased garment worn with an average of 3.12 uses (76\% of impact contribution from production), has a lower impact than the rental scenario with increased users/rentals (PSS 1.1, 1.2, and 1.3).

The variation for transport scenarios for HTPc shows that the PSS scenarios with car transport have the highest impact, followed by the low-use linear scenario (L 1.2), then the low-use PSS scenarios (PSS 1.2 with the public transport modes), as shown in Figure A1. If the scenarios with the high-impact transportation mode are excluded, production accounts for a higher impact in this category, as it contributes to $81 \%$ of the impact in L 1.2, and $64 \%$ of the impact in PSS 1.2 (Figure A1). L 1.3 has the lowest impact, followed by PSS 1.3 with nearly the same percentage contribution as $\mathrm{L} 1.1$. This indicates again that increased usage for purchased garments has potentially the lowest or nearly the same impact as high usage in a rental scenario when consumers use public transportation modes. Although high usage in rental scenarios greatly decreases the share of impacts resulting from production (Figure $4 \mathrm{~b}$ ), the increased share of rental transportation in these scenarios contributes a greater impact than increased owner usage. 


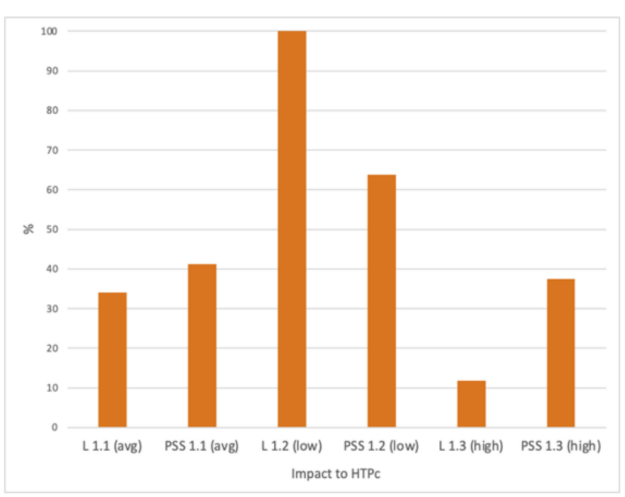

(a)

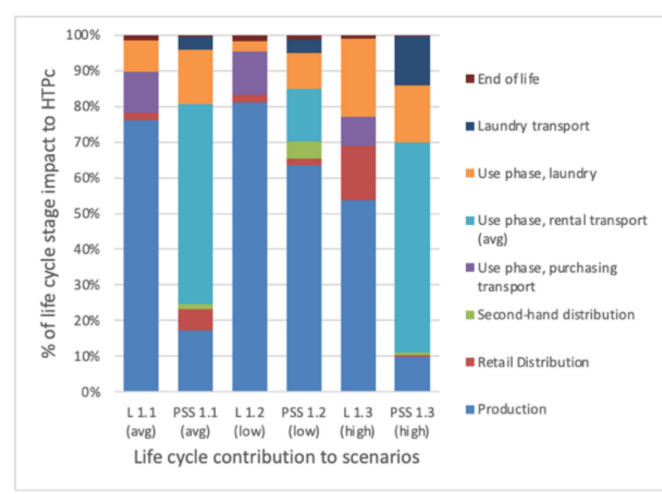

(b)

Figure 4. Characterisation results by the percentage of the impact of linear vs. rental scenarios for HTPc for "one average use". The highest scores of the category are set to $100 \%$ and other values are set as a relative percent (a); Life-cycle stage contribution to the total impact for HTPc for each scenario (b).

While Figure 5 indicates that one average use in a PSS BM has a lower carbon footprint than the linear BM with average and low use (PSS 1.1 has a lower GWP than L 1.1, and PSS 1.2 is lower than L 1.2), PSS 1.2 has a higher carbon footprint than L 1.1, indicating that increased use of owned garments in a linear scenario has a lower carbon footprint than renting clothes if garments are not rented or used enough times. Furthermore, PSS 1.3 with a high amount of users has a higher GWP than L 1.3 with high-use because of the large amount of use-phase transport in the PSS models. The impact contribution from transport increases with increased users and rental while the share of the production impact decreases in the PSS scenarios, and the increased use in purchased garments results in a reduced carbon footprint as the share of production impact decreases. This indicates that the use intensification of garments already in ownership can offer greater savings in an individual's carbon footprint than engaging in rental clothing when rental requires a high amount of transport per rental transaction. Different combinations of transport modes show that the linear scenario with the highest number of uses (L 1.3) has the lowest carbon footprint, followed by the high-use PSS scenarios with public transport scenarios (see Figure A2). However, the average and high-use PSS scenarios with car transport are both higher than the average and high-use linear scenarios. This is noteworthy, as when comparing linear to rental scenarios, rental business models should be in good proximity to consumers to encourage walking/biking and use of public transport, and to reduce overall impact from transport. Furthermore, rental BMs should be in locations that do not incentivize driving. 


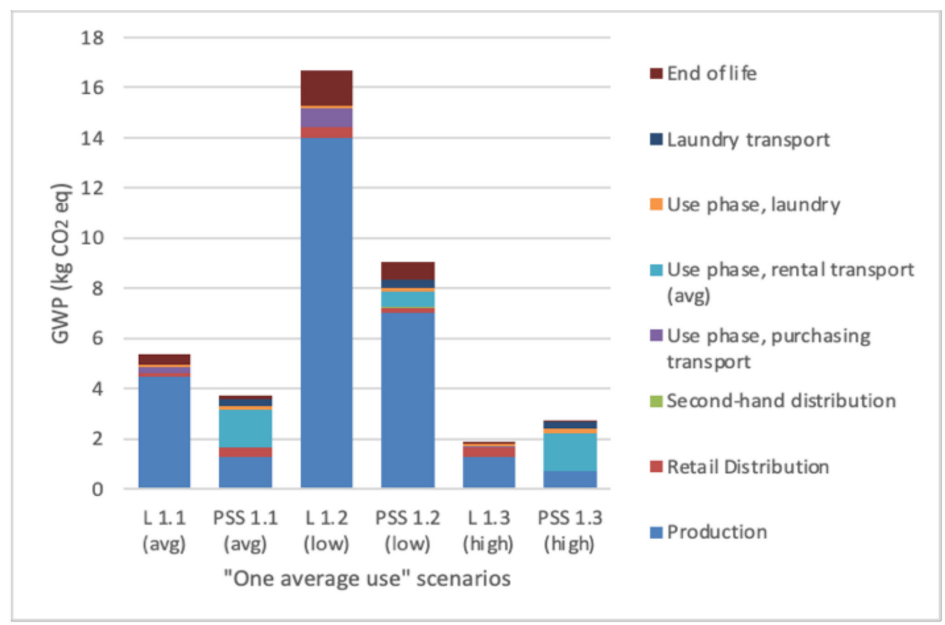

Figure 5. Impact of scenarios in $\mathrm{kg} \mathrm{CO}_{2}$ eq for global warming potential with life-cycle stage contribution for the "one average use" scenarios.

\subsection{Consumer Dress Satisfaction by Purchasing}

The scenarios for the FU " 4 years of consumer formal dress needs satisfied by purchasing" show how differences in the RR of rental for purchased dresses change the impact of consumption. Since rental clothing was not found to substitute ownership of dresses completely, the PSS system also includes some purchased clothing.

The linear scenario (L 2) has the highest impact contribution to freshwater ecotoxicity potential (see Figure 6a). With an increase in the RR, the impact in the PSS scenarios decreases, which can be attributed to the decreased need for production. This is shown where the percentage share of production in the overall impact to the category decreases from L 2 to PSS 2.3, meaning that the impact of transportation is less significant than production in this category (Figure $6 \mathrm{~b}$ ). The impact for PSS 2.3 with the $100 \%$ RR is $67 \%$ less of the environmental impact of $\mathrm{L} 2$ for freshwater ecotoxicity, indicating the potential for full substitution for purchased dresses, as PSS 2.2 is 44\% less, and PSS 2.1 is $33 \%$ less than the impact for the linear scenario. Adjusted transportation scenarios (see Figure A3) with high-impact transportation show that the benefit of a high RR in PSS 2.3 is negated and has a much larger impact on freshwater ecotoxicity, even more so than the linear scenario. The linear scenario (L 2) has around $60 \%$ less impact than the PSS scenarios with the high-impact transport modes. However, the PSS scenarios with public transport modes all have lower impacts than the linear scenario.

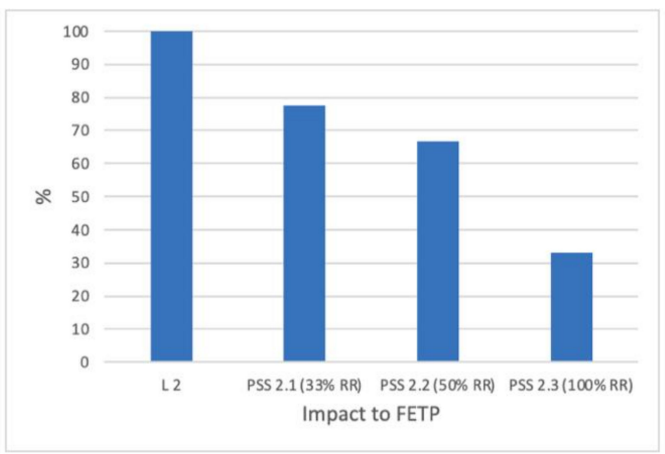

(a)

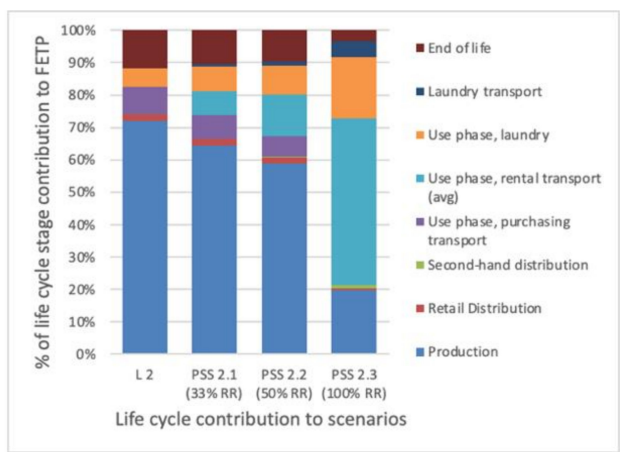

(b)

Figure 6. Characterisation results by percentage of impact of linear vs. rental scenarios for FETP, for " 4 years of consumer needs by purchasing". The highest scores of the category are set to $100 \%$ and other values set as a relative percent (a); Life-cycle stage contribution to the total impact for FETP for each scenario (b). 
The contribution for human carcinogenic toxicity shows that the linear scenario (L 2) contributes the most impact to this category compared to the rental scenarios (see Figure 7a). This is followed by the PSS scenarios with the lowest RR. The impact from PSS 2.1 with a $33 \%$ RR has $20 \%$ less impact for human carcinogenic toxicity than L 2, with PSS 2.2 with the 50\% RR having 30\% less, and PSS 2.3 with 100\% RR for purchased clothing with $60 \%$ less impact in this category than the linear scenario. The decrease in impact to this category is associated with the decrease in the overall share of production impacts, as shown in Figure $7 \mathrm{~b}$. In the adjusted transport scenarios for the human carcinogenic toxicity category, the PSS scenarios with the highest RR and high-impact transport become the highest impact contributors over L 2 (see Figure A3). PSS 2.1 has a 7\% higher impact, PSS 2.2 with $11 \%$ higher impact, and PSS 2.3 with 21\% higher impact when modelling with car transport. All other transport scenarios for the PSS scenarios have a lower impact than the linear scenario.

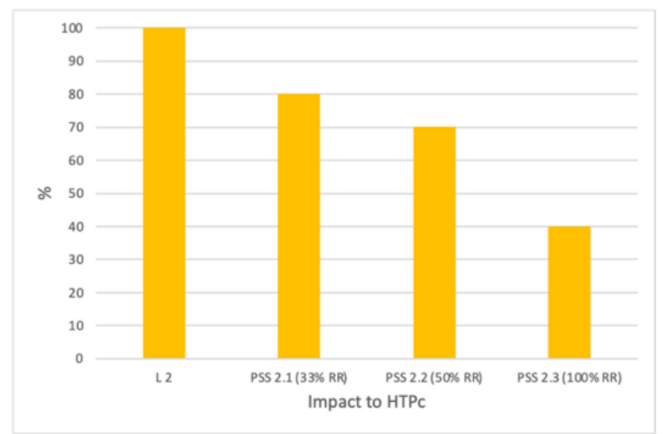

(a)

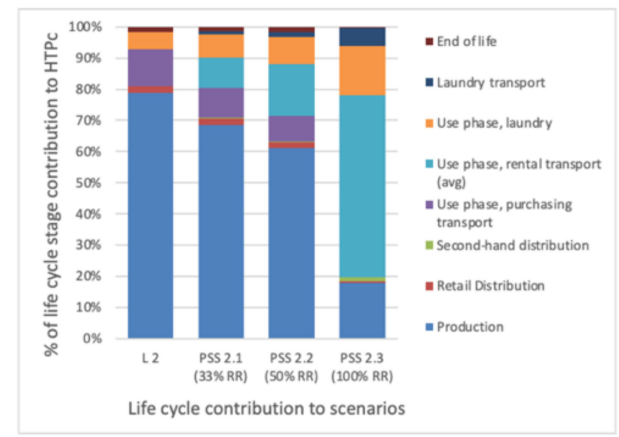

(b)

Figure 7. Characterisation results by percentage of impact of linear vs. rental scenarios for HTPc, for " 4 years of consumer needs by purchasing". The highest scores of the category are set to $100 \%$ and other values set as a relative percent (a); Life-cycle stage contribution to the total impact for HTPc for each scenario (b).

Figure 8 shows a decrease in global warming potential with an increase in the RR, indicating that individual carbon savings can be $80 \%$ less if rental clothing substitutes $100 \%$ of the need to purchase. If rental clothing substitutes just half of purchasing needs, there are $40 \%$ savings, and if rental substitutes $33 \%$, there are $27 \%$ savings in $\mathrm{kg} \mathrm{CO}_{2}$ eq per person. When testing alternative transport modes, as shown in Figure A4, all PSS scenarios have less impact on GWP than the linear scenario (L2) even when including the high-impact transport modes. PSS 2.3 with the $100 \%$ RR and high-impact transport mode has 5\% less impact contribution to GWP than PSS 2.1 with average transport and $33 \%$ RR. It however has a 10\% higher impact than PSS 2.2 with the $50 \%$ RR and average transport. This indicates that the use of high-impact transportation modes can have less impact if it is associated with a high RR for purchased garments in comparison to low $\mathrm{RR}$, but there is a threshold where the impacts from transport overtake the impacts from decreased production, as shown with the PSS 2.2 scenario. 


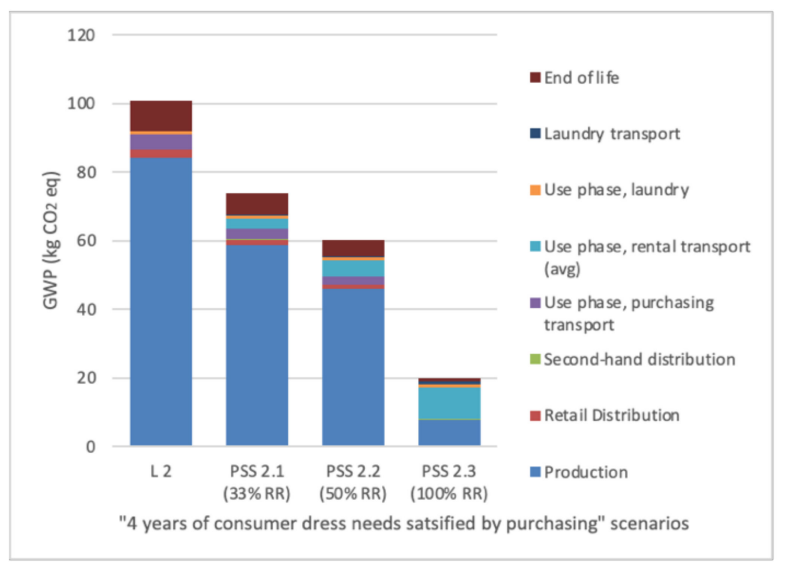

Figure 8. Impact of scenarios in $\mathrm{kg} \mathrm{CO} 2$ eq for global warming potential with life-cycle stage contribution the " 4 years of consumer dress needs satisfied by purchasing" scenarios.

\subsection{Consumer Dress Satisfaction by Use}

The scenarios for the FU "4 years of consumer formal dress needs satisfied by use" show how differences in the RR of rental for purchased dress wear occasions change the impact of consumption. Similar scenarios are set up as in the previous section, however, the RR is now applied to the number of uses, or wear occasions not the number of garments purchased.

The impact on freshwater ecotoxicity potential has very little difference between the scenarios. PSS 3.1 with the 33\% RR for the number of wear occasions for rental over purchased has the lowest impact. PSS 3.2 with the $50 \%$ RR has a $2 \%$ higher impact than PSS 3.1 and the linear scenario (L 3) (Figure 9a). PSS 3.2 also has a 1\% higher impact than PSS 3.3 with the $100 \%$ RR. This indicates that if consumers are using rental dresses to replace one use or wear occasion for clothing, then an increase in the number of uses from rental is not beneficial with increased transport and with the need to purchase dresses. This is shown in PSS 3.2 with a 50\% RR, where an increase in the number of rental dresses used just once with combined purchasing has a higher impact. PSS 3.3 with a 100\% RR has a slightly lower impact than PSS 3.2, indicating the potential benefit of just rental. Variations in the transport mode for freshwater ecotoxicity have relatively the same impact across all scenarios from the linear scenario to all PSS scenarios, excluding the PSS scenarios with the high-impact transport scenarios. PSS scenarios using car transport have between 3-10 times more percentage than the other scenarios, as shown in Figure A5.

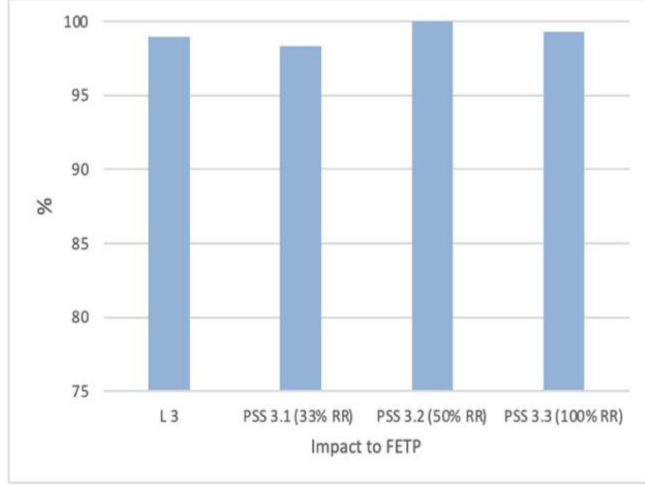

(a)

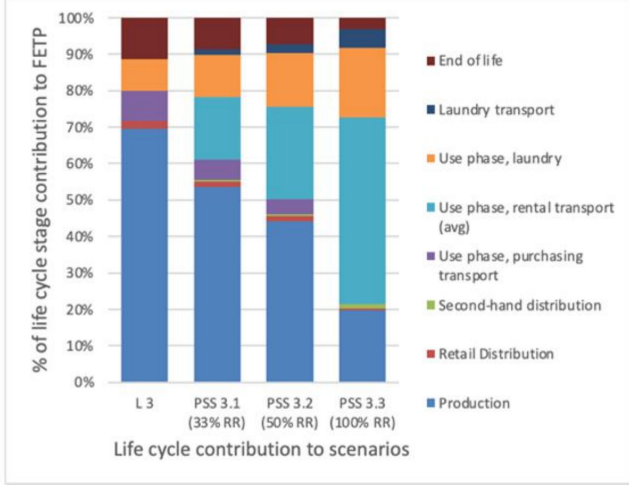

(b)

Figure 9. Characterisation results by percentage of impact of linear vs. rental scenarios for FETP for " 4 years of consumer needs satisfied by use". The highest scores of the category are set to $100 \%$ and other values set as a relative percent (a); Life-cycle stage contribution to the total impact for FETP for each scenario (b). 
PSS 3.3 has the highest amount of impact contribution to human carcinogenic toxicity, with the linear scenario as the lowest (L3), with 18\% less impact (see Figure 10a). The impact increases with the increase in the replacement rate for use, which indicates that high transport associated with increased RR for rental contributes the most to human carcinogenic ecotoxicity potential, as shown in (Figure 10b). When testing different transport scenarios, there is no significant variation in the results, except for the high-impact transport scenarios (see Figure A5).

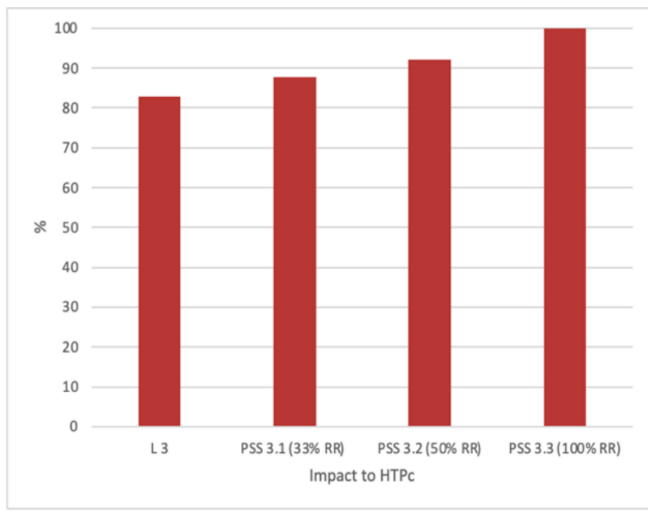

(a)

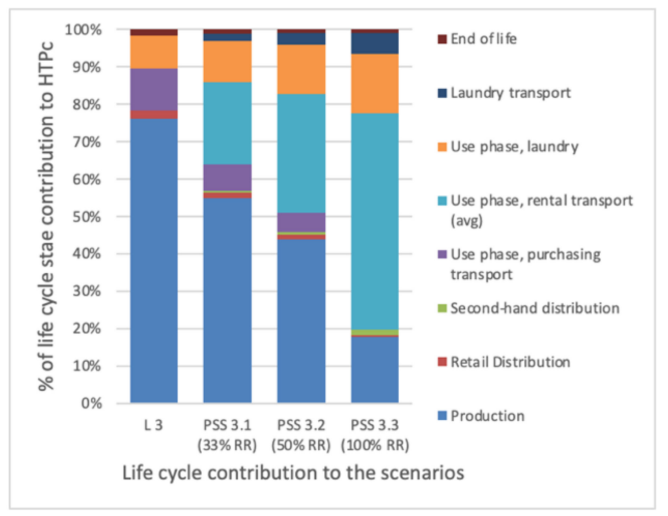

(b)

Figure 10. Characterisation results by percentage of impact of linear vs. rental scenarios for HTPc for " 4 years of consumer needs satisfied by use". The highest scores of the category are set to $100 \%$ and other values set as a relative percent (a); Life-cycle stage contribution to the total impact for HTPc for each scenario (b).

The impacts on GWP decrease with the increased replacement of wear occasions by rental dresses, as a result of the decrease of production contribution (see Figure 11). Since transportation in the rental company is a large portion of the activity associated with rental due to the need for logistics and reverse logistics, Figure A6 indicates that that the renting of clothing can have a higher impact on GWP than purchasing if consumers use high-impact transport modes. Since the results are associated with RR for use, it is logical that the scenarios with higher RRs have a larger impact with the transport scenarios involving cars since more travel is associated with each use. It should be noted that this differs from Figures 8 and A4, as the RR for that functional unit is associated with the rental replacement of purchased garments.

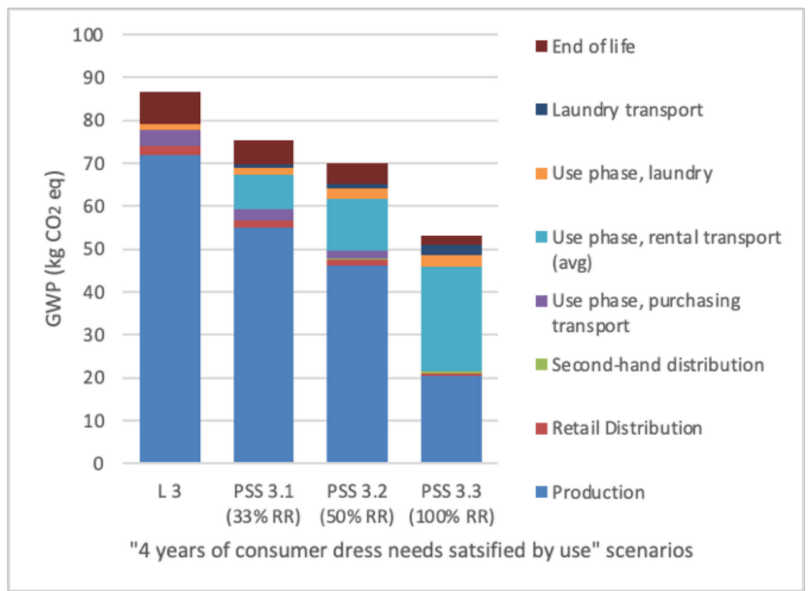

Figure 11. Impact of scenarios in $\mathrm{kg} \mathrm{CO}_{2}$ eq for global warming potential with life-cycle stage contribution the " 4 years of consumer dress needs satisfied by use" scenarios. 


\section{Discussion}

The following section summarises the impact of user behaviour in PSSs on the LCA results and the implications of the results for more sustainable consumer action and business models. It then discusses the importance of the selected impact categories as well as data and research limitations.

\subsection{User Behaviour Variation and Impact on LCA Results}

The environmental savings potential that a PSS can have is influenced heavily by how consumers choose to engage with rental BMs. This is shown in how many times consumers use garments, how they use rental to substitute or complement their purchasing or use needs, and how they choose to travel to rental store locations.

Consumers' use intensity of garments is important both in the linear and PSS BM. Increased use intensity of clothes they already own or have purchased can significantly decrease the environmental impacts of production. Consumers can also increase their use intensity of garments in the same rental period to reduce their impact from transportation, as well as engage in more rentals if they use low-impact transportation modes.

The RR of rental for purchased dresses plays an important role in discerning the environmental benefit of rental clothing. Users who rent solely in addition to normal purchasing are not creating any benefit, however, as their engagement with rental reduces the need to purchase and produce products, the benefit of rental increases.

Variation in transport modes was only modelled for consumer transport to the rental store, and results between the high-impact transport and other transport modes were significant. Users who choose to take public transportation modes, such as the metro and bus combination, metro and walking, and cycling and metro scenarios can significantly reduce their impact and increase the environmental potential for clothing rental. Consumers who use high-impact transport such as cars, negate the benefit that a PSS could have and result in a higher impact than linear scenarios.

A summary of the highest and lowest contributing scenarios is summarised in Table 3. While the first two functional units are consistent across impact categories in the highest and lowest contributing scenarios, the last functional unit's scenarios varied in the contribution for each impact category. However, in interpreting the impacts for the three analysed FUs, the benefits of PSS are more apparent when considering the change in effect that renting dresses can have on consumption and the impact of production. This is shown in the "four-year" scoped FUs, while the "one average use" FU shows a limited perspective and benefit that a PSS may have.

Table 3. Most impactful scenarios from FUs.

\begin{tabular}{cccc}
\hline Functional Unit & Impact & Highest Contributor & Lowest Contributor \\
\hline \multirow{2}{*}{ One average use } & FETP & Linear scenario with low & Linear scenario with high \\
& HTPc & use (L 1.2) & use (L 1.3) \\
4 years of consumer & FETP & & PSS scenario with 100\% RR \\
formal dress needs & HTPc & Linear scenario (L 2) & (PSS 2.3) \\
satisfied by purchasing & GWP & & PSS with 33\% RR (PSS 3.1) \\
4 years of consumer & FETP & PSS with 50\% RR (PSS 3.2) & Linear scenario (L3) \\
formal dress needs & HTPc & PSS with 100\% RR (PSS 3.3) & PSS with 100\% RR (PSS 3.3) \\
satisfied by use & GWP & Linear scenario (L3) &
\end{tabular}

\subsection{Consumer Behaviour and Business Model Implications}

This case study analysed a niche company offering rental formal dresses, a concept that is not new since rental formalwear has been around for several years, notably with the company, Rent the Runway in the US. Although this case study focuses on a specific product, the results are illustrative to interpret and map the environmental potential for 
other types of garments or products, as well as understand the type of infrastructure needed to support low-impact transport of products in PSSs.

The general low-use intensity and need for special-occasion wear suggest the potential to lower production impacts by increasing the overall usage of these types of garments. Although a decrease in garment production is beneficial, the associated transport needed to facilitate one garment rental creates a high impact that could reduce the PSS's potential for environmental impact savings. PSSs must encourage increased use not only through multiple rentals, but also for one user to wear the same garment many times during the rental period. This could perhaps be facilitated by longer rentals, e.g., a few months rather than a few days or a week. However, this type of rental scenario will likely not work for special-occasion wear, such as in the case company. If consumers are looking for unique garments for certain events, it renders the reuse of a garment as impractical by the same renter. However, longer rental time frames would be an important attribute for casual rental wear companies to have. Casual renting clothing could include anything from jeans to jackets, to more everyday clothing such as shirts. Longer rental time frames can also apply to PSSs offering other products where ownership can be wasteful and inconvenient, but where users may need a certain product for a slightly longer term, such as rental furniture to students.

Special-occasion wear rental companies can focus on securing locations that are central and require little or low-impact transportation, or find low-impact delivery services to facilitate forward and reverse logistics. For example, bike-delivery in cities with supportive cycling infrastructure. In locations with low public transportation services and longer distances, such as in the US where cars are often necessary, PSSs may not be the most environmental option if consumers must facilitate the pick-up and drop-off. However, PSSs in more remote locations could use more mainstream delivery methods to consumer homes, or set up distribution and redistribution networks. This for example could involve collaborations with small stores for multiple pick-up and drop-off locations, such as done with Wardrobe, a rental clothing company in New York that collaborates with local laundromats as part of its pick-up and drop-off network.

Although the different FUs imply slightly different suggestions for the best alternative actions for consumer behaviour and business model structure, general takeaways for consumer behaviour and clothing rental business models are suggested from the results to offer more sustainable options for clothing consumption.

Consumer behaviour implications:

- Consumers should purchase garments only if they will keep and wear them many times. They should avoid purchasing clothing items that they would only wear a few times;

- If consumers rent a garment, they should wear it multiple times during that rental period;

- Consumers who rent clothing should use rental to fully replace their purchasing needs and avoid partial substitution;

- Consumers should completely avoid driving to rental locations and combine trips to the rental store with other travel plans.

Business model implications:

- Traditional retail BMs should create garments that last long in terms of style durability. Then material and technical durability should follow to support customers' increased usage;

- $\quad$ Rental BMs should increase the use of garments per rental period by offering longer rental periods and disincentivising one-use rentals. For example, pay-per-use schemes should be avoided;

- Rental BMs should offer a large enough inventory to provide enough variety and selection for consumers to use rental as a full replacement for purchasing;

- Rental companies should reduce transport needs within their company, for example, with laundry; 
- Rental companies should have pick-up and drop-off locations in shorter distances to consumers' homes.

\subsection{Choice and Relevance of LCA Impact Categories}

Three impact categories were included in this study: two categories that were shown as most significant (FETP and HTPc), and GWP which was analysed in addition. Although these impact categories are perceived as relevant when consulting previous LCAs for garments, assessing all the impact categories would provide a more holistic overview of the impact of both systems. Impact categories or indicators often reported in industrial assessment appear to not be the most significant impacts, as suggested by this study. For example, the company Reformation uses RefScale, an LCA tool to calculate the $\mathrm{CO}_{2}$, water use, and waste footprints of their garments [78]. The Higg Material Sustainability Index (Higg MSI), created by the Sustainable Apparel Coalition and used commonly in the apparel industry assesses four impact categories: global warming, eutrophication, water scarcity, and abiotic resource depletion/fossil fuels [77]. This study analysed the commonly reported impact category of GWP, which showed positive results for the rental scenarios. However, results were slightly more mixed with the significant categories, which are not typically assessed in the industry. Industries must assess the broad impacts of production throughout various impact categories and justify the assessment of their chosen impact categories when creating products.

\subsection{Data Limitations and Assumptions}

The scope of the study was specifically on formal dress consumption. This does not, for example, account for how dress purchasing or rental could incentivise other purchases, e.g., the potential indirect rebound effects of consumption. For example, the ability for consumers to wear dresses for cheaper through rental could incentivise them to buy other accessories, such as shoes that they previously could not afford, or buy more of something else. This is not accounted for in the LCA study, as it would require a more comprehensive behaviour study and would better be suited to consider in a consequential LCA approach or other modelling methods, such as an environmentally-extended input-output assessment or other econometric tools. Data gaps are always present in LCIs [64], but this research utilised data triangulation to select the most relevant and reliable data for the case study. However, it is important to discuss how the data selection and assumptions made affect the overall results.

Production data was based on secondary data provided by literature, and the material modelled (polyester) was consistent with the common material composition for dresses in the case company. The various impacts from different materials and fibres are not tested in this study, although the material used could affect the overall durability of garments, the number of washes required, and the potential for garments to be upcycled and/or recycled. The material of garments also affects the upstream processes of extraction of resources to produce fibres. Modelling of a cotton dress instead of polyester could perhaps have had a larger water footprint, although this was not analysed.

Consumer behaviour data was based on the survey, which reflects a very specific respondent group. Although the data was compared to literature, data was primarily used from the survey since the information was highly specific to formal dresses, while the literature generalised garments and all dresses. The consumer purchasing frequency was calculated based on consumer responses from the survey. The purchasing frequency likely differs in different cities, as well as countries, where the number of dresses purchased could change based on the affordability of dresses in the region, the strength of the secondhand market, and the community atmosphere (if dresses are shared informally between family or friends). The change in purchasing frequency could then alter the environmental consequences of both systems under analysis. The average use intensity of purchased formal dresses in the survey was much lower than that found in literature, although this is 
attributed to the specific types of dresses that are rented in the case study, in comparison to generalised garments analysed in the literature.

The laundry frequency was estimated based on the weighted average of consumer responses and the average number of uses from the survey, and may be slightly higher or lower for consumers perhaps than actual behaviour. A wash cycle was assumed to be a small load of $1 \mathrm{~kg}$, in which the impact of one wash cycle is attributed to one dress, although dresses are half the load size. Since a dress must be washed no matter if there are other items to be washed with it, the burden was allocated to the dress. A wash cycle was also assumed to be filled with water to the average load of $3.4 \mathrm{~kg}$, despite the washing of a smaller load. This likely increased the impact of laundry, however as laundry had a little significance compared to other life-cycle stages, it assumed that these factors would not have changed the overall impact for the scenarios. Since garments are assumed to be washed at $30{ }^{\circ} \mathrm{C}$ due to the delicate nature and synthetic material of the dresses, this lowers the impact compared to the average $40{ }^{\circ} \mathrm{C}$ wash cycle used for many types of garments and casual wear. The share of impact from laundry could change if consumers use higher impact washing machine programs or drying techniques, however, possible laundry behaviour variations were not included in the study. Laundry does not play a significant role in this study, but this may change if assessing the impact in other countries where the electricity mix might be considerably higher than that of Sweden.

Although variations in transport mode were tested, an average distance of $20 \mathrm{~km}$ for one trip (to the store and back) was assumed for all scenarios. When considering the impact for rental transportation, smaller distances than the assumed average distance would have decreased the impact associated with rental scenarios, although it is unknown how large of a distance variation would be significant. Assumptions were made on the number of dresses accumulated at the same time by the case company in the second-hand redistribution process. The impact of transport could be much less if more dresses are collected at the same time, however, there was no data on this. For consumer transport, the transport to purchase or rent a dress is often combined with other purposes or errands for a transport trip, as shown from the survey, in which the impact from transportation would be reduced if there were multiple reasons for a trip. However, this is not accounted for due to the complexity in allocating the burden of transport to multiple stops, and still $45 \%$ of respondents stated they make a point to go just to the rental store. However, $55 \%$ did state they go on multiple errands, which would decrease the share of impact coming from rental transportation and could likely change the overall environmental impact of a few scenarios. This observation can be solved through the traditional allocation approaches practiced in LCA, but these require either more insights into other co-processes (i.e., the extent and the nature of other errands) or could be based on some simple partitioning, which is even more subjective. Moreover, more insights would be needed into reasons for travel, for example, whether dress rental triggers other errands or vice versa. This was not in the scope, nor was it practical during the study.

Although delivery for consumers is optional and offered by the case company, this was not modelled, as only 8 out of 856 consumers have chosen home delivery. The impact for laundry transport, although was shared for multiple dresses, contributed to an increase in rental scenarios, when transport was likely associated with employees coming to and from work daily, in which the burden should also be allocated in the system. However, employee transportation was not included in the modelled system, and so the burden was allocated entirely to laundry, as the trip is necessary regardless of whether the employee comes to or from work daily.

The EoL scenarios were highly simplified, and there is likely the potential for a decrease in the overall impact of linear and rental scenarios if a more complex situation were modelled. In a linear scenario, a formal dress in good condition is likely shared informally by being given to friends or family or sent to a second-hand store or redistribution store (as in the case for dresses procured by the case company). The increased use of a dress before its EoL would also help decrease the share of impacts from production. The case company 
has plans to donate their old dresses beyond repair to a company that uses old materials in new dresses. This is not accounted for in the EoL scenarios since the case company is relatively new and has not done this yet, nor has data on how much material would be reused. The EoL scenario modelled also does not include credited heat or electricity from the incineration of waste in Sweden, as this goes beyond the ALCA approach.

\section{Conclusions}

Acknowledging the need to change the apparel industry's current practices, this research examined the potential of a clothing PSS by quantifying the environmental impacts of consumption in a rental clothing company in Stockholm and compared it to a linear business model. The LCA study took a consumer perspective to understand the potential for rental clothing to displace purchased clothing. How users decide to engage with rental BMs dictates the environmental savings potential that a PSS can have, as shown in how many times consumers wear garments, how they use rental to substitute their purchasing or use needs, and how consumers travel to rental store locations. The case study offered a perspective on how BMs can innovate their activities and services to influence positive consumer behaviour and reduce impact.

As society begins to transition away from business-as-usual, and the fashion industry moves away from a take-make-dispose economy and towards circular strategies and sharing principles, it is important to not identify a blueprint of a business model as the most sustainable for all contexts. Business models with sustainability potential should be retrofit to each context and case, from the geographic location to the product and the consumer market. Business models such as PSSs do have potential when given the right conditions to cultivate, and PSSs can play an important role in shifting traditional consumption thinking and slowly dissolving consumers' connection to ownership and products. Industry leaders can help to pave the way by honing their business models to provide a choice architecture for consumers to behave sustainably.

Supplementary Materials: The following are available online at https:/ /www.mdpi.com/2071-105 0/13/4/2118/s1, Table S1: Functional units (FUs) and descriptions, Table S2: Product reference flow calculations and justification, Table S3: Wear occasions reference flow calculations and justification, Table S4: Transportation reference flow calculations and justification, Table S5:Laundry reference flow calculations and justification, Table S6: Municipal reference flow calculations and justification, Table S7: Characterisation results for "one average use" scenarios, Table S8: Characterisation results for "one average use" scenarios with transportation variation, Table S9: Characterisation results for " 4 years of dress needs by purchasing" scenarios, Table S10: Characterisation results for "4 years of dress needs by purchasing" scenarios with transportation variation, Table S11: Characterisation results for " 4 years of dress needs by use" scenarios, Table S12: Characterisation results for "4 years of dress needs by use" scenarios with transportation variation

Author Contributions: Conceptualization, E.J.; methodology, E.J.; software, E.J.; validation, E.J. and A.P.; formal analysis, E.J.; investigation, E.J.; resources, E.J.; data curation, E.J.; writing—original draft preparation, E.J.; writing - review and editing, E.J. and A.P.; visualization, E.J. and A.P.; supervision, E.J. and A.P.; project administration, E.J.; funding acquisition, A.P. All authors have read and agreed to the published version of the manuscript.

Funding: This research received no external funding.

Institutional Review Board Statement: Not Applicable.

Informed Consent Statement: Informed consent was obtained from all subjects involved in the study.

Data Availability Statement: Additional data is available in the Supplementary Materials. Restrictions apply to the availability of further specific data utilised in the LCA. Data was obtained from the ecoinvent v3 database that was made available by license through Simapro Version 9.0 from PRé Sustainability. 
Acknowledgments: Thank you to Ana Maria Arbelaez Velez for support in the initial life-cycle stage modelling and to Philip Peck for review of the draft. This research has been supported by the Mistra REES program.

Conflicts of Interest: The authors declare no conflict of interest.

\section{Appendix A}

Table A1. Most popular travel modes from consumer survey used to model transport variations in LCA.

\begin{tabular}{ccc}
\hline Transport Scenarios & Primary Mode & Secondary Mode \\
\hline Average & Metro & Bus \\
T2 & Metro & Walking \\
T3 & Biking & Metro \\
T4 & Car & Metro \\
\hline
\end{tabular}

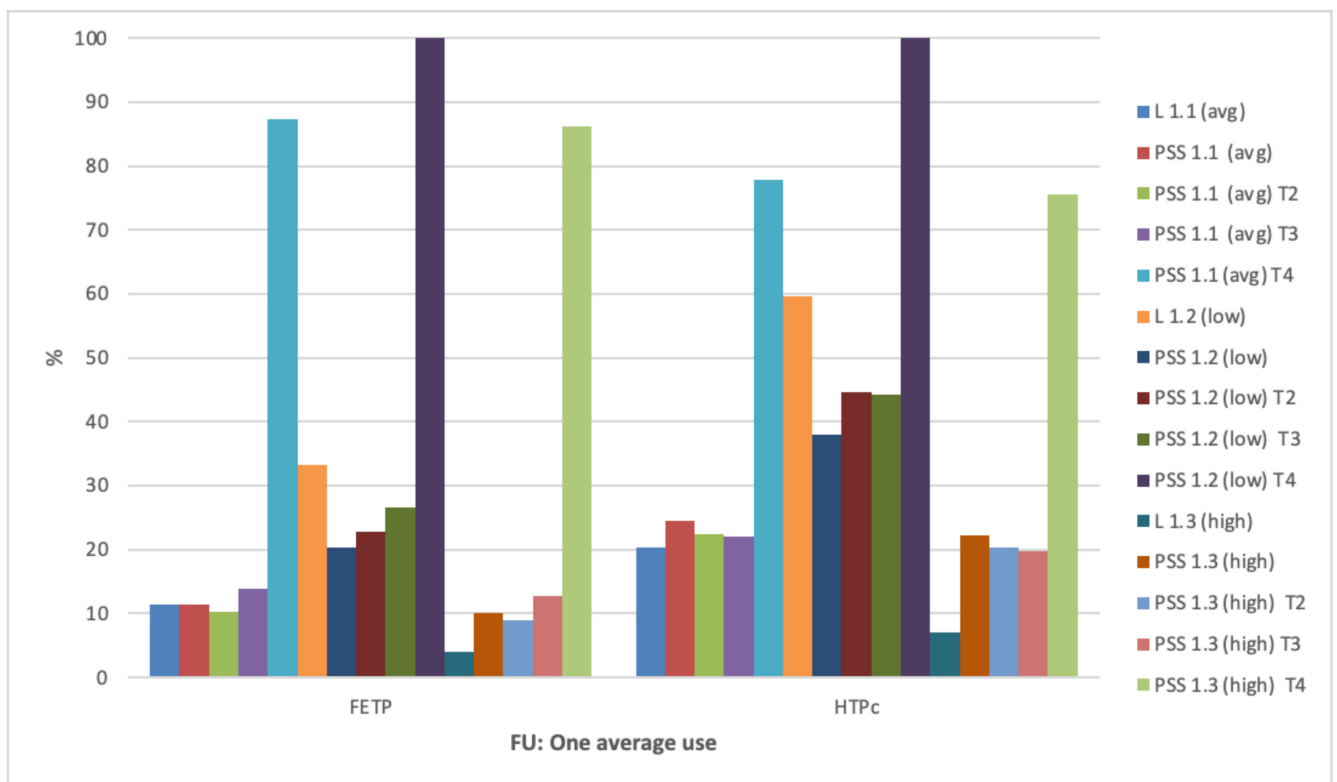

Figure A1. Characterisation results for significant categories with all scenarios for "one average use" with adjusted transportation scenarios for consumer rental transport. The highest scores of the category are set to $100 \%$ and other values set as a relative percent. Note that categories should not be compared to another in this figure, only comparison of scenarios within one impact category. No $\mathrm{T}$ indicates average transport with metro and bus, $\mathrm{T} 2=$ metro and walking, $\mathrm{T} 3=$ bike and metro, and $\mathrm{T} 4=$ car and metro. 


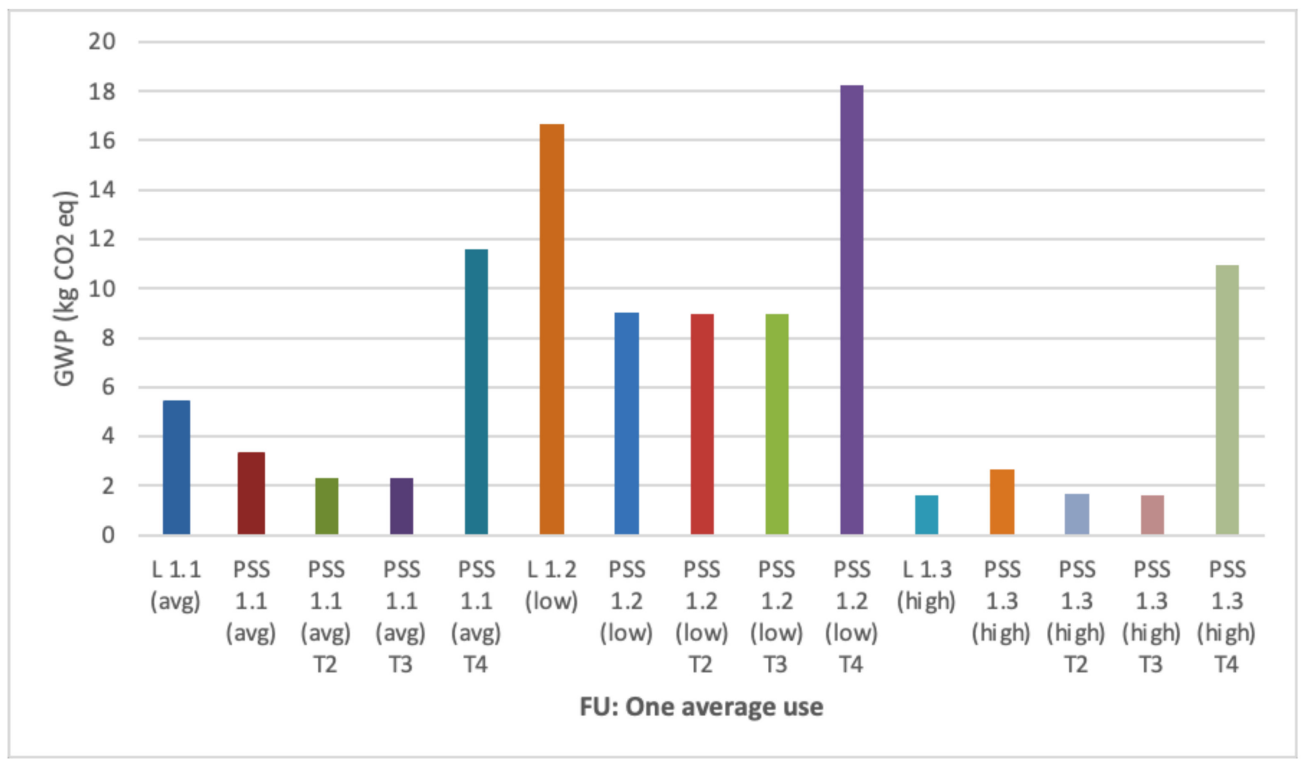

Figure A2. Global warming potential of "one average use" where no T indicates average transport with metro and bus, $\mathrm{T} 2=$ metro and walking, $\mathrm{T} 3=$ bike and metro, and $\mathrm{T} 4=$ car and metro.

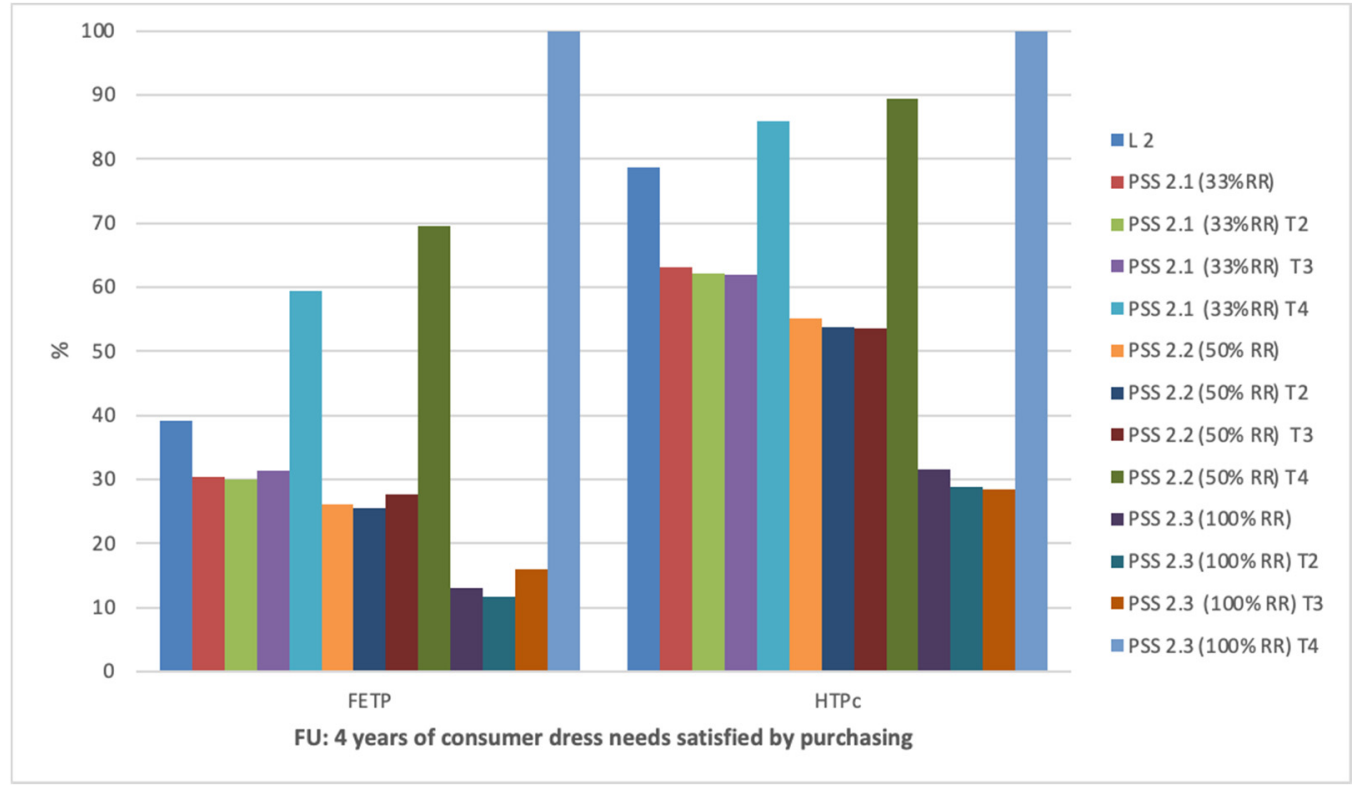

Figure A3. Characterisation results for significant categories with all scenarios for " 4 years of consumer dress needs satisfied by purchasing" with adjusted transportation scenarios for consumer rental transport. The highest scores of the category are set to $100 \%$ and other values as a relative percent. Note that categories should not be compared to another in this figure, only comparison of scenarios within one impact category. No $\mathrm{T}$ indicates average transport with metro and bus, $\mathrm{T} 2=$ metro and walking, $\mathrm{T} 3=$ bike and metro, and $\mathrm{T} 4=$ car and metro. 


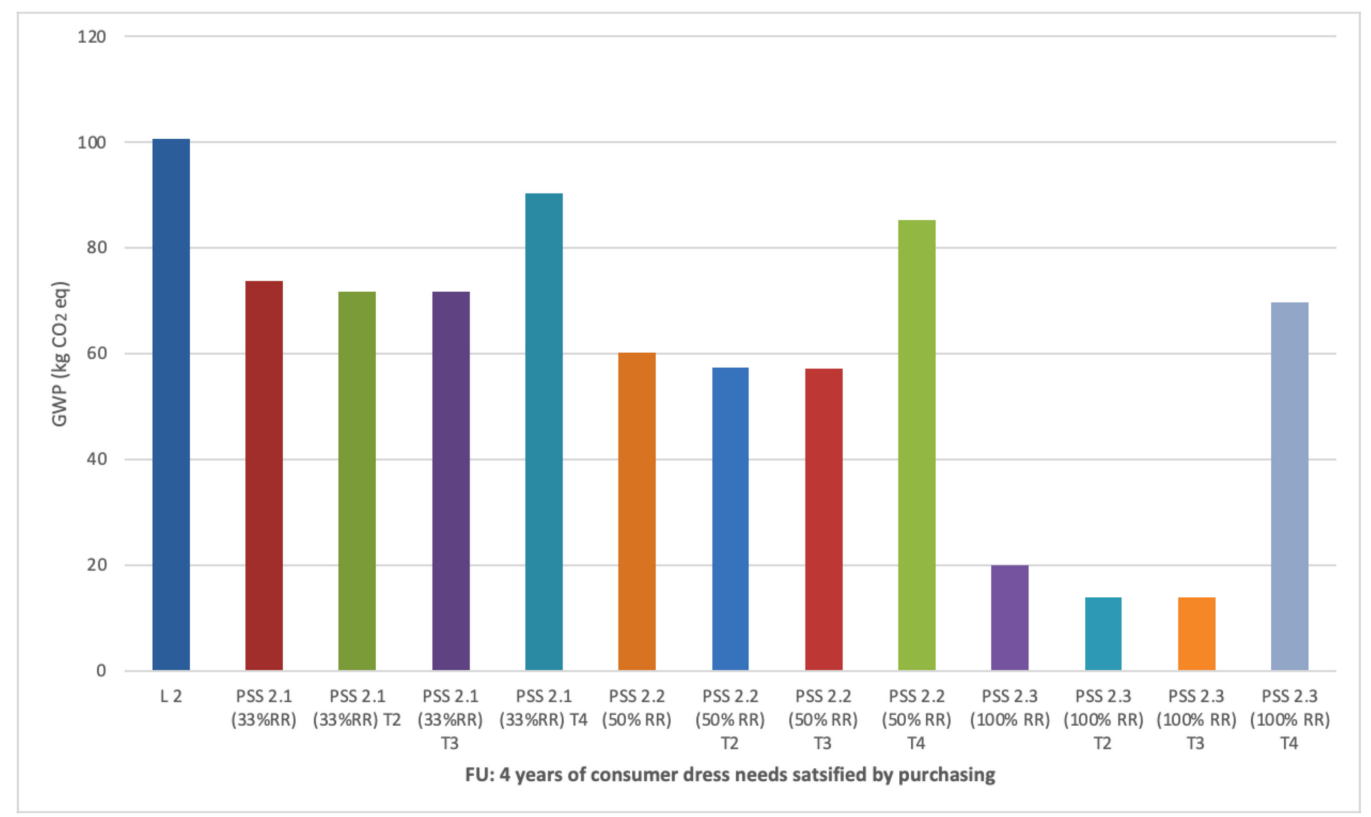

Figure A4. Global warming potential of " 4 years of consumer dress needs satisfied by purchasing" with different RRs and transport adjustments for rental where no $\mathrm{T}$ indicates average transport with metro and bus, T2 = metro and walking, T3 = bike and metro, and T4 = car and metro.

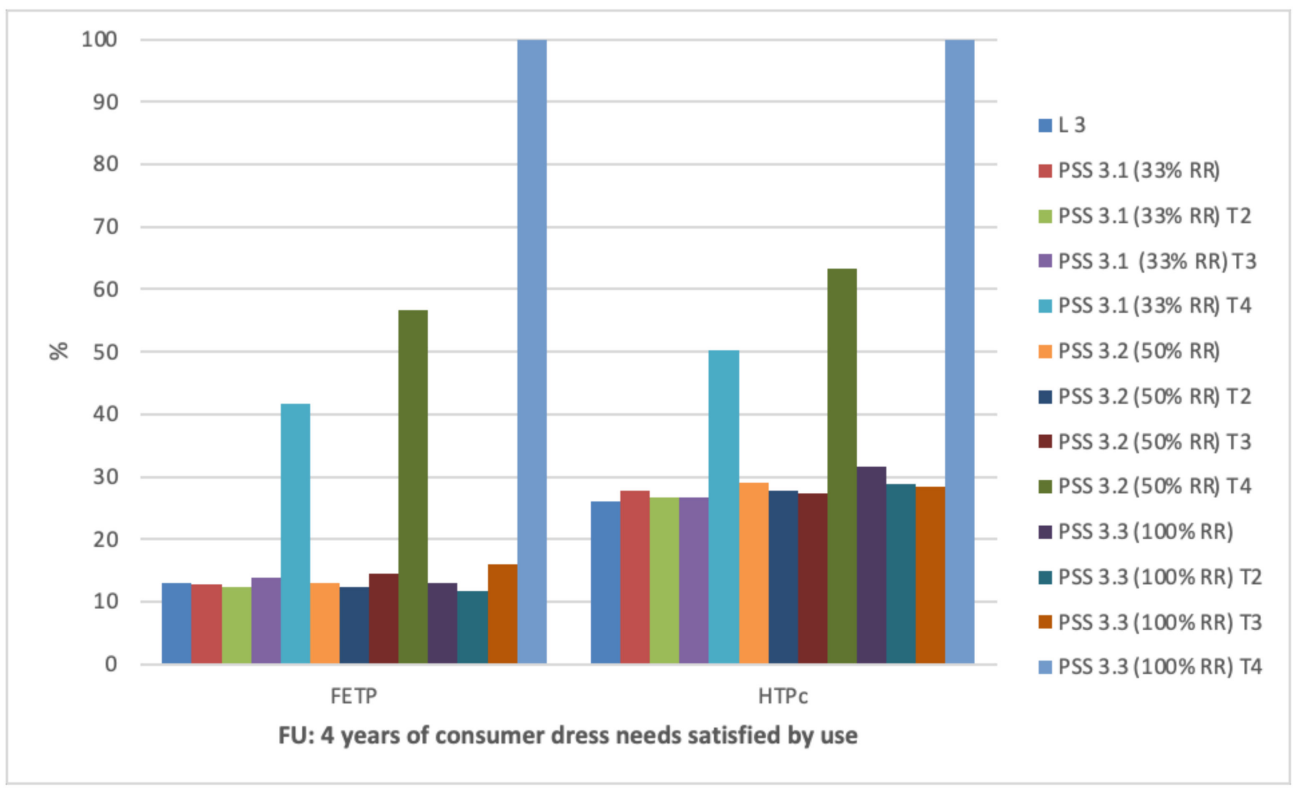

Figure A5. Characterisation results for significant categories with all scenarios for "4 years of consumer dress needs satisfied by use" with adjusted transportation scenarios for consumer rental transport. The highest scores of the category are set to $100 \%$ and other values as a relative percent. Note that categories should not be compared to another in this figure, only comparison of scenarios within one impact category. No T indicates average transport with metro and bus, $\mathrm{T} 2=$ metro and walking, T3 = bike and metro, and T4 = car and metro. 


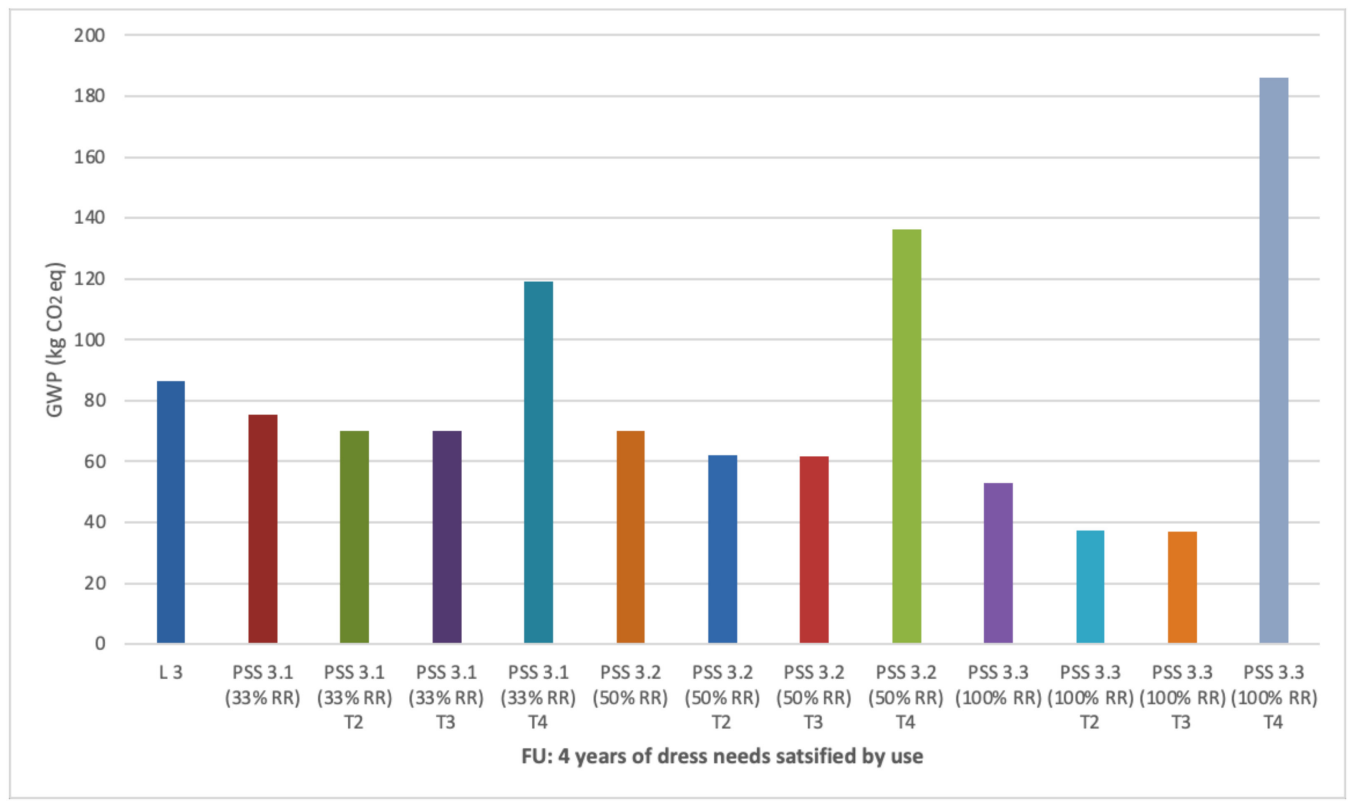

Figure A6. Global warming potential of "4 years of consumer dress needs satisfied by use" with different RRs and transport adjustments for rental where no $\mathrm{T}$ indicates average transport with metro and bus, $\mathrm{T} 2$ = metro and walking, $\mathrm{T} 3=$ bike and metro, and $\mathrm{T} 4$ = car and metro.

\section{References}

1. Piontek, F.M.; Müller, M. Literature Reviews: Life Cycle Assessment in the Context of Product-Service Systems and the Textile Industry. Procedia CIRP 2018, 69, 758-763. [CrossRef]

2. Ellen MacArthur Foundation. A New Textile's Economy: Redesigning Fashion's Future; Ellen MacArthur Foundation: Cowes, UK, 2017.

3. Roos, S.; Sandin, G.; Zamani, B.; Peters, G.; Svanström, M. Will Clothing Be Sustainable? Clarifying Sustainable Fashion. In Textiles and Clothing Sustainability: Implications in Textiles and Fashion; Muthu, S.S., Ed.; Springer: Singapore, 2017 ; pp. $2-45$.

4. Naturvårdsverket Textilkonsumtion, Kilo per Person i Sverige. Available online: http://www.naturvardsverket.se/Sa-marmiljon/Statistik-A-O/Textil/? (accessed on 1 March 2020).

5. Hultén, J.; Johansson, M.; Dunsö, O.; Jensen, C. Plockanalyser Av Textilier i Hushållens Restavfall; SMED (Svenska MiljöEmissionsData): Norrköping, Sweden, 2016.

6. Belleza, E.; Luukka, E. Svenska Textilflöden- Textilflöden Från Välgörenhet Och Utvalda Verksamheter; SMED (Svenska MiljöEmissionsData): Norrköping, Sweden, 2018.

7. Pohl, J.; Suski, P.; Haucke, F.; Piontek, F.M.; Jäger, M. Beyond Production-the Relevance of User Decision and Behaviour in LCA. In Progress in Life Cycle Assessment 2018; Teuteberg, F., Hempel, M., Schebek, L., Eds.; Springer International Publishing: Cham, Switzerland, 2019; pp. 3-19. ISBN 978-3-030-12265-2.

8. Mont, O.; Whalen, K.; Nussholz, J. Sustainable innovation in business models: celebrated but not interrogated. In Handbook of Sustainable Innovation; Boons, F., McMeekin, A., Eds.; Routledge: London, UK, 2019; pp. 124-140. ISBN 978-1-78811-257-4.

9. Pal, R. Extended Responsibility through Servitization in PSS: An Exploratory Study of Used-Clothing Sector. J. Fash. Mark. Manag. Int. J. 2016, 20, 453-470. [CrossRef]

10. Tukker, A. Product Services for a Resource-Efficient and Circular Economy-A Review. J. Clean. Prod. 2015, 97, 76-91. [CrossRef]

11. Castellani, V.; Sala, S.; Mirabella, N. Beyond the Throwaway Society: A Life Cycle-Based Assessment of the Environmental Benefit of Reuse: LCA of Second-Hand Shops. Integr. Environ. Assess. Manag. 2015, 11, 373-382. [CrossRef] [PubMed]

12. Global Fashion Agenda and McKinsey \& Company. CEO Agenda 2020: COVID-19 Edition; Global Fashion Agenda and McKinsey \& Company: New York, NY, USA, 2020.

13. Ellen MacArthur Foundation. The Circular Economy: A Transformative Covid-19 Recovery Strategy: How Policymakers Can Pave the Way to a Low Carbon, Prosperous Future; Ellen MacArthur Foundation: Cowes, UK, 2020.

14. thredUP. 2019 Resale Report; thredUP: San Francisco, CA, USA, 2019.

15. Sposato, P.; Preka, R.; Cappellaro, F.; Cutaia, L. Sharing Economy and Circular Economy. How Technology and Collaborative Consumption Innovation Boost Closing the Loop Strategies. Environ. Eng. Manag. J. 2017, 16, 1797-1806. [CrossRef]

16. Böcker, L.; Meelen, T. Sharing for People, Planet or Profit? Analysing Motivations for Intended Sharing Economy Participation. Environ. Innov. Soc. Transit. 2017, 23, 28-39. [CrossRef]

17. Martin, M.; Lazarevic, D.; Gullström, C. Assessing the Environmental Potential of Collaborative Consumption: Peer-to-Peer Product Sharing in Hammarby Sjöstad, Sweden. Sustainability 2019, 11, 190. [CrossRef] 
18. Saksanian, C.; Martínez-Fiestas, M.; Timana, J.S. What Pulls Consumers in and What Pushes Consumers Out. In Sharing Economy and the Impact of Collaborative Consumption; de Luna, I.R., Fitó-Bertran, À., Lladós-Masllorens, J., Liébana-Cabanillas, F., Eds.; IGI Global: Hershey, PA, USA, 2020; pp. 164-184. ISBN 978-1-5225-9928-9.

19. Amaya, J.; Lelah, A.; Zwolinski, P. Design for Intensified Use in Product-Service Systems Using Life-Cycle Analysis. J. Eng. Des. 2014, 25, 280-302. [CrossRef]

20. Amasawa, E.; Shibata, T.; Sugiyama, H.; Hirao, M. Environmental Potential of Reusing, Renting, and Sharing Consumer Products: Systematic Analysis Approach. J. Clean. Prod. 2020, 242, 118487. [CrossRef]

21. Birtwistle, G.; Moore, C.M. Fashion Clothing-Where Does It All End Up? Int. J. Retail Distrib. Manag. 2007, 35, 210-216. [CrossRef]

22. Iran, S.; Schrader, U. Collaborative Fashion Consumption and Its Environmental Effects. J. Fash. Mark. Manag. Int. J. 2017, 21, 468-482. [CrossRef]

23. Lang, C.; Armstrong, C.M.J. Fashion Leadership and Intention toward Clothing Product-Service Retail Models. J. Fash. Mark. Manag. Int. J. 2018, 22, 571-587. [CrossRef]

24. Zink, T.; Geyer, R. Circular Economy Rebound: Circular Economy Rebound. J. Ind. Ecol. 2017, 21, 593-602. [CrossRef]

25. Zamani, B.; Sandin, G.; Peters, G.M. Life Cycle Assessment of Clothing Libraries: Can Collaborative Consumption Reduce the Environmental Impact of Fast Fashion? J. Clean. Prod. 2017, 162, 1368-1375. [CrossRef]

26. Verboven, H.; Vanherck, L. The Sustainability Paradox of the Sharing Economy. UWF UmweltWirtschaftsForum 2016, $24,303-314$. [CrossRef]

27. Pedersen, E.R.G.; Earley, R.; Andersen, K.R. From Singular to Plural: Exploring Organisational Complexities and Circular Business Model Design. J. Fash. Mark. Manag. Int. J. 2019, 23, 308-326. [CrossRef]

28. Corvellec, H.; Stål, H.I. Evidencing the Waste Effect of Product-Service Systems (PSSs). J. Clean. Prod. 2017, 145, 14-24. [CrossRef]

29. Sandin, G.; Peters, G.M. Environmental Impact of Textile Reuse and Recycling-A Review. J. Clean. Prod. 2018, 184, 353-365. [CrossRef]

30. Dahlbo, H.; Aalto, K.; Eskelinen, H.; Salmenperä, H. Increasing Textile Circulation-Consequences and Requirements. Sustain. Prod. Consum. 2017, 9, 44-57. [CrossRef]

31. Piontek, F.M.; Rehberger, M.; Müller, M. Development of a Functional Unit for a Product Service System: One Year of Varied Use of Clothing. In Progress in Life Cycle Assessment; Schebek, L., Herrmann, C., Cerdas, F., Eds.; Springer International Publishing: Cham, Switzerland, 2019; pp. 99-104. ISBN 978-3-319-92236-2.

32. Schmidt, A.; Watson, D.; Roos, S.; Askham, C.; Brunn Poulson, P. Gaining Benefits from Discarded Textiles. LCA of Different Treatment Pathways; Nordisk Ministerråd: Copenhagen, Denmark, 2016; p. 155.

33. Farrant, L.; Olsen, S.I.; Wangel, A. Environmental Benefits from Reusing Clothes. Int. J. Life Cycle Assess. 2010, 15, 726-736. [CrossRef]

34. Kjaer, L.L.; Pigosso, D.C.A.; Niero, M.; Bech, N.M.; McAloone, T.C. Product/Service-Systems for a Circular Economy: The Route to Decoupling Economic Growth from Resource Consumption? J. Ind. Ecol. 2019, 23, 22-35. [CrossRef]

35. Kjaer, L.L.; Pagoropoulos, A.; Schmidt, J.H.; McAloone, T.C. Challenges When Evaluating Product/Service-Systems through Life Cycle Assessment. J. Clean. Prod. 2016, 120, 95-104. [CrossRef]

36. Doualle, B.; Medini, K.; Boucher, X.; Laforest, V. Investigating Sustainability Assessment Methods of Product-Service Systems. Procedia CIRP 2015, 30, 161-166. [CrossRef]

37. Muñoz López, N.; Santolaya Sáenz, J.L.; Biedermann, A.; Serrano Tierz, A. Sustainability Assessment of Product-Service Systems Using Flows between Systems Approach. Sustainability 2020, 12, 3415. [CrossRef]

38. Lüdeke-Freund, F.; Gold, S.; Bocken, N.M.P. A Review and Typology of Circular Economy Business Model Patterns. J. Ind. Ecol. 2019, 23, 36-61. [CrossRef]

39. Osterwalder, A.; Pigneur, Y. Business Model Generation: A Handbook for Visionaries, Game Changers, and Challengers; John Wiley and Sons: Hoboken, NJ, USA, 2010.

40. Teece, D.J. Business Models, Business Strategy and Innovation. Long Range Plann. 2010, 43, 172-194. [CrossRef]

41. Zott, C.; Amit, R.; Massa, L. The Business Model: Recent Developments and Future Research. J. Manag. 2011, 37, 1019-1042. [CrossRef]

42. Bocken, N.M.P.; Short, S.W.; Rana, P.; Evans, S. A Literature and Practice Review to Develop Sustainable Business Model Archetypes. J. Clean. Prod. 2014, 65, 42-56. [CrossRef]

43. Piscicelli, L.; Cooper, T.; Fisher, T. The Role of Values in Collaborative Consumption: Insights from a Product-Service System for Lending and Borrowing in the UK. J. Clean. Prod. 2015, 97, 21-29. [CrossRef]

44. Armstrong, C.M.; Niinimäki, K.; Lang, C.; Kujala, S. A Use-Oriented Clothing Economy? Preliminary Affirmation for Sustainable Clothing Consumption Alternatives. Sustain. Dev. 2016, 24, 18-31. [CrossRef]

45. Mont, O. Clarifying the Concept of Product-Service System. J. Clean. Prod. 2002, 10, 237-245. [CrossRef]

46. Tukker, A. Eight Types of Product-Service System: Eight Ways to Sustainability? Experiences from SusProNet. Bus. Strategy Environ. 2004, 13, 246-260. [CrossRef]

47. Johnson, E. Dressing up the Environmental Potential for Product-Service Systems: A Comparative Life Cycle Assessment on Consumption in Rental Clothing vs. Linear Business Models. Master's Thesis, International Institute for Industrial Environmental Economics, Lund University, Lund, Sweden, 2020. 
48. Somers, L.; Dewit, I.; Baelus, C. Understanding Product-Service Systems in a Sharing Economy Context-A Literature Review. Procedia CIRP 2018, 73, 173-178. [CrossRef]

49. Bocken, N.M.P.; Olivetti, E.A.; Cullen, J.M.; Potting, J.; Lifset, R. Taking the Circularity to the Next Level: A Special Issue on the Circular Economy. J. Ind. Ecol. 2017, 21, 476-482. [CrossRef]

50. Ellen MacArthur Foundation. Delivering the Circular Economy: A Toolkit for Policymakers; Ellen MacArthur Foundation: Cowes, UK, 2015.

51. European Commission. Towards a Circular Economy: A Zero Waste Programme for Europe; Communication from the Commission to the European Parliament, the Council, the European Economic and Social Committee and the Committee of the Regions: Brussels, Belgium, 2014.

52. Chen, Z.; Huang, L. Application Review of LCA (Life Cycle Assessment) in Circular Economy: From the Perspective of PSS (Product Service System). Procedia CIRP 2019, 83, 210-217. [CrossRef]

53. Camacho-Otero, J.; Boks, C.; Pettersen, I.N. User Acceptance and Adoption of Circular Offerings in the Fashion Sector: Insights from User-Generated Online Reviews. J. Clean. Prod. 2019, 231, 928-939. [CrossRef]

54. Holtström, J.; Bjellerup, C.; Eriksson, J. Business Model Development for Sustainable Apparel Consumption: The Case of Houdini Sportswear. J. Strategy Manag. 2019, 12, 481-504. [CrossRef]

55. Blaikie, N.; Priest, J. Designing Social Research: The Logic of Anticipation; Wiley: Hoboken, NJ, USA, 2019; ISBN 978-1-5095-1741-1.

56. Scholz, R.W.; Tietje, O. Embedded Case Study Methods: Integrating Quantitative and Qualitative Knowledge; SAGE: Thousand Oaks, CA, USA, 2002.

57. Yin, R. Case Study Research: Design and Methods, 5th ed.; SAGE Publications: Thousand Oaks, CA, USA, 2014.

58. Flyvbjerg, B. Five Misunderstandings About Case-Study Research. Qual. Inq. 2006, 12, 219-245. [CrossRef]

59. Curwen, L.G.; Park, J.; Sarkar, A.K. Challenges and Solutions of Sustainable Apparel Product Development: A Case Study of Eileen Fisher. Cloth. Text. Res. J. 2013, 31, 32-47. [CrossRef]

60. Piontek, F.M.; Amasawa, E.; Kimita, K. Environmental Implication of Casual Wear Rental Services: Case of Japan and Germany. Procedia CIRP 2020, 90, 724-729. [CrossRef]

61. Piontek, F.M.; Rapaport, M.; Müller, M. One Year of Clothing Consumption of a German Female Consumer. Procedia CIRP 2019, 80, 417-421. [CrossRef]

62. Sandin, G.; Roos, S.; Spak, B.; Zamani, B.; Peters, G. Environmental Assessment of Swedish Clothing Consumption-Six Garments, Sustainable Futures; Mistra Future Fashion, RISE AB: Göteborg, Sweden, 2019.

63. WRAP. Valuing Our Clothes: The Cost of UK Fashion; WRAP: Banbury, UK, 2017.

64. Baumann, H.; Tillman, A.-M. The Hitchhiker's Guide to LCA: An Orientation in Life Cycle Assessment Methodology and Application; Studentlitteratur: Lund, Sweden, 2004; ISBN 978-91-44-02364-9.

65. Ekvall, T. Attributional and Consequential Life Cycle Assessment. In Sustainability Assessment at the 21st century; IntechOpen: London, UK, 2020; ISBN 978-1-78984-976-9.

66. Finnveden, G.; Hauschild, M.Z.; Ekvall, T.; Guinée, J.; Heijungs, R.; Hellweg, S.; Koehler, A.; Pennington, D.; Suh, S. Recent Developments in Life Cycle Assessment. J. Environ. Manag. 2009, 91, 1-21. [CrossRef]

67. European Commission-JRC-IES International Reference Life Cycle Data System (ILCD) Handbook: General Guide for Life Cycle Assessment_Detailed Guidance; Publications Office of the European Union: Luxembourg, 2010.

68. Goedkoop, M.; Oele, M.; Leijting, J.; Ponsioen, T.; Meijer, E. Introduction to LCA with SimaPro; PRé: San Francisco, CA, USA, 2016.

69. Ecoinvent Allocation Cut-off by Classification. Available online: https://www.ecoinvent.org/database/system-models-inecoinvent-3/cut-off-system-model/allocation-cut-off-by-classification.html (accessed on 1 March 2020).

70. Roos, S.; Sandin, G.; Zamani, B.; Peters, G. Environmental Assessment of Swedish Fashion Consumption. Five Garments-Sustainable Futures; Mistra Future Fashion: Stockholm, Sweden, 2015.

71. Granello, S.; Jönbrink, A.; Roos, S.; Johansson, T.; Granberg, H. Consumer Behaviour on Washing; Mistra Future Fashion: Stockholm, Sweden, 2015.

72. Presutto, M.; Stamminger, R.; Scialdoni, R.; Mebane, W.; Esposito, R.; Faberi, S. Domestic Washing Machines and Dishwashers. In Preparatory Studies for Eco-Design Requirements of EuP.; Öko-Institut: Freiburg im Breisgau, Germany, 2007.

73. Pakula, C.; Stamminger, R. Electricity and Water Consumption for Laundry Washing by Washing Machine Worldwide. Energy Effic. 2010, 3, 365-382. [CrossRef]

74. Palm, D.; Elander, M.; Watson, D.; Kiørboe, N.; Salmenperä, H.; Dahlbo, H.; Moliis, K.; Lyng, K.-A.; Valente, C.; Gíslason, S.; et al. Towards a Nordic Textile Strategy: Collection, Sorting, Reuse and Recycling of Textiles; Norden: Copenhagen, Denmark, 2014.

75. Sleeswijk, A.W.; van Oers, L.F.C.M.; Guinée, J.B.; Struijs, J.; Huijbregts, M.A.J. Normalisation in Product Life Cycle Assessment: An LCA of the Global and European Economic Systems in the Year 2000. Sci. Total Environ. 2008, 390, 227-240. [CrossRef] [PubMed]

76. PRé. SimaPro Database Manual: Methods Library; PRé: Amersfoort, The Netherlands, 2019.

77. Watson, K.J.; Wiedemann, S.G. Review of Methodological Choices in LCA-Based Textile and Apparel Rating Tools: Key Issues and Recommendations Relating to Assessment of Fabrics Made From Natural Fibre Types. Sustainability 2019, 11, 3846. [CrossRef]

78. Reformation Sustainability Report. A Year in Review. 2019. Available online: https://www.thereformation.com/pages/2019 -year-in-review (accessed on 1 April 2020). 